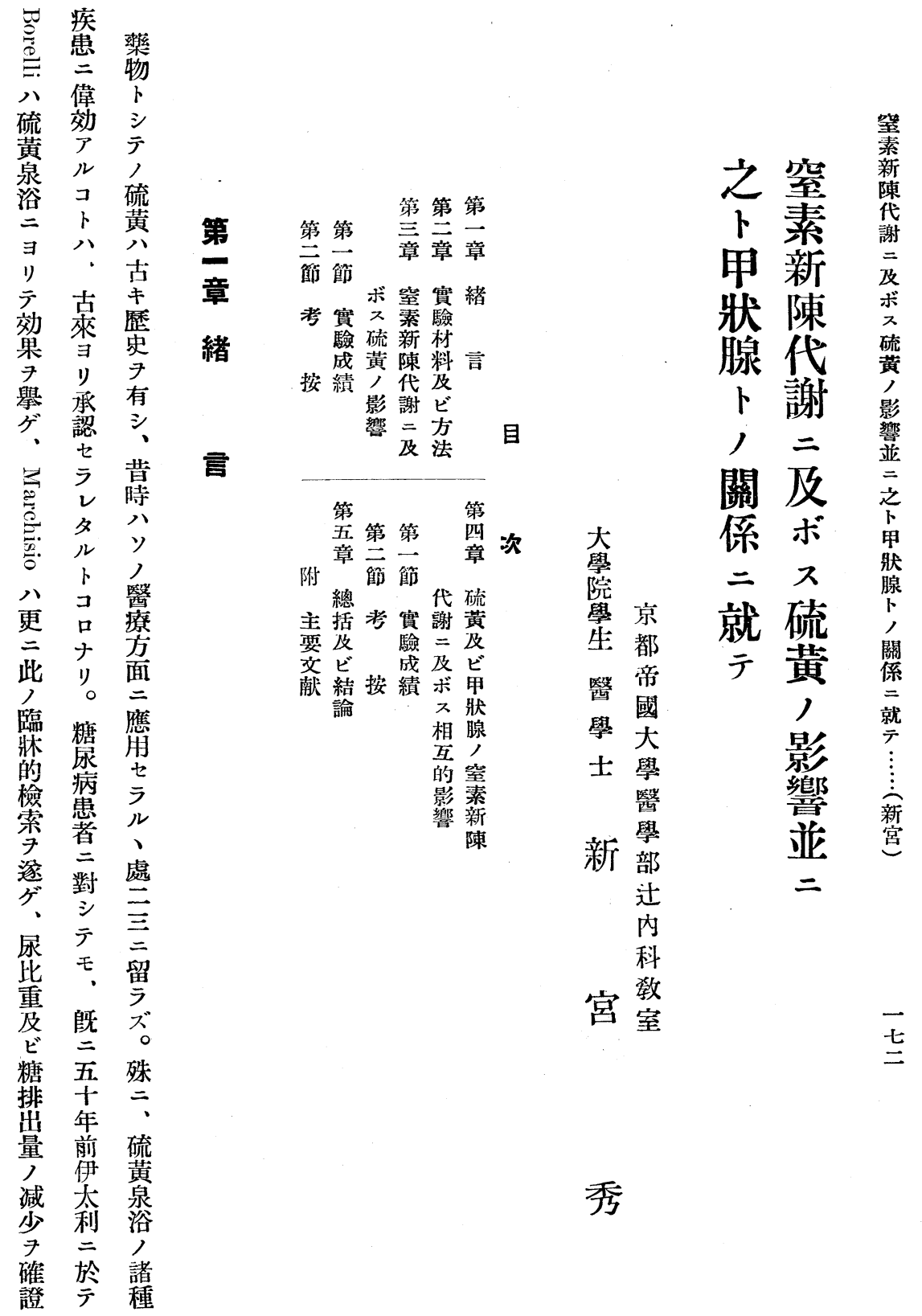




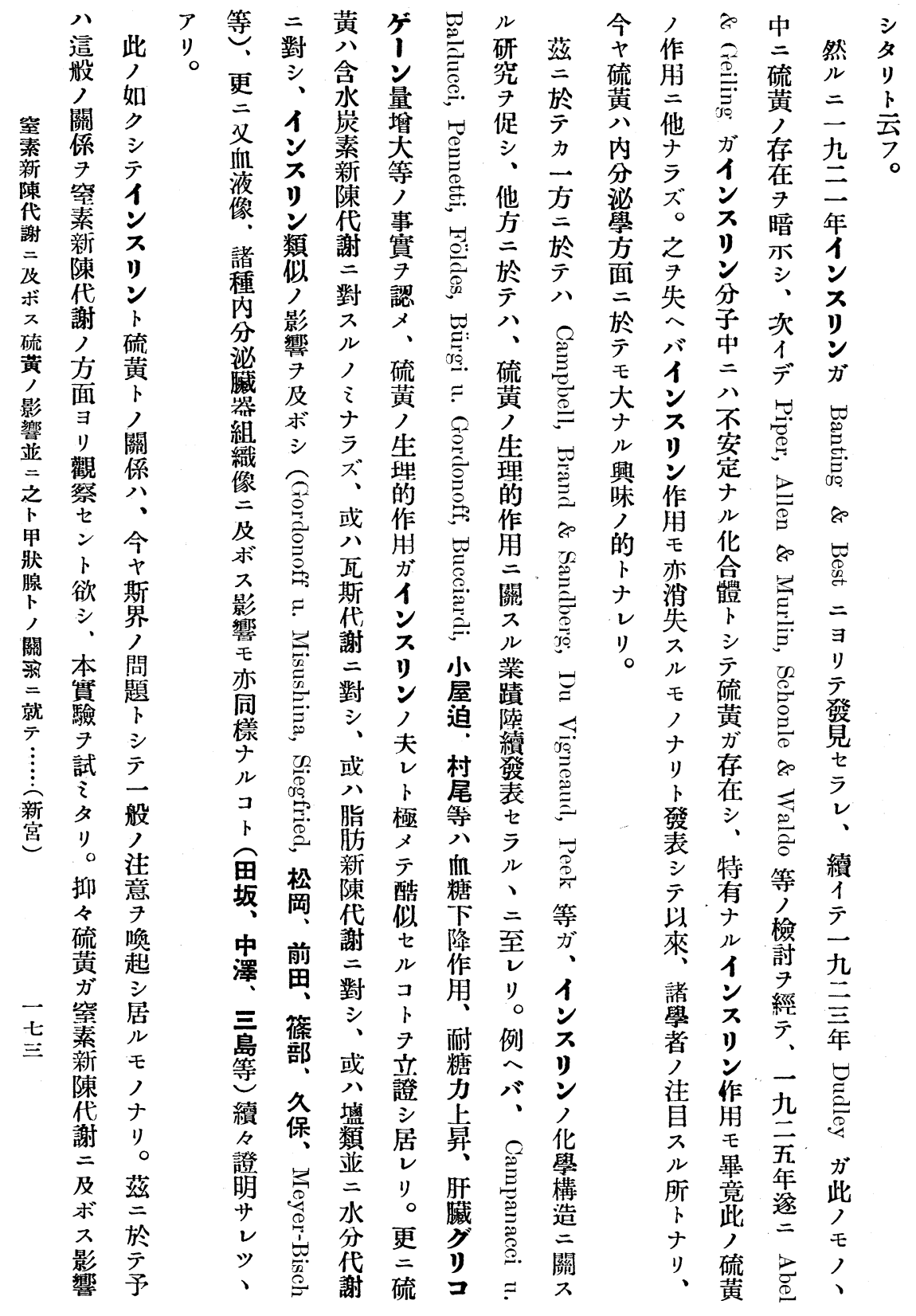




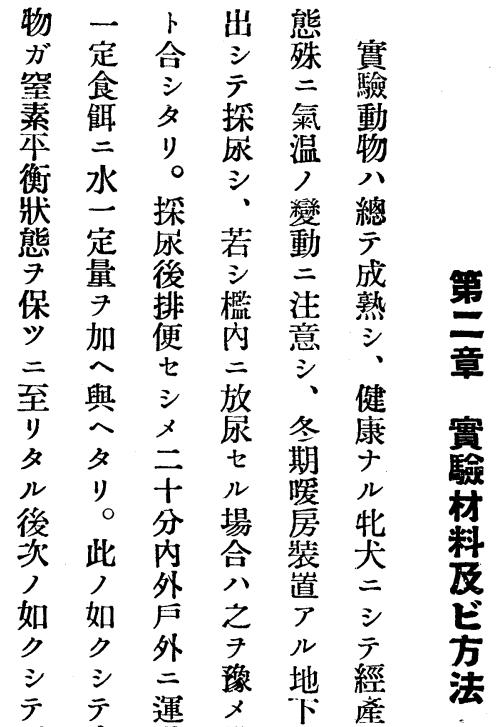

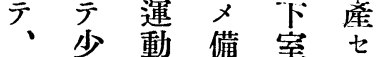

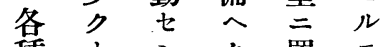

種トシタ置モ

成モメルキ

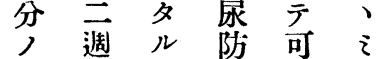

定間後鹰亘角

行卢垂者同七

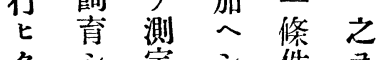

タ シ 定 シ 件 タ

”。文再硝市定

即尿 ビ 瓶二,

于中檻二在新

上窒 二集

述素收少三代

如排 、㠰 、謝

ク泄而之每二

示略 亏 之

得々 後贞定主

夕一別探時

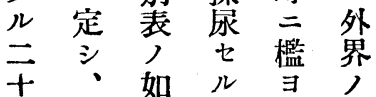

四動分分狀

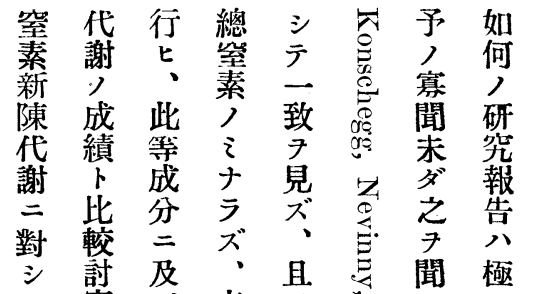

究 ボ主兴势謝

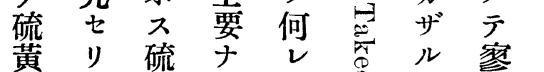

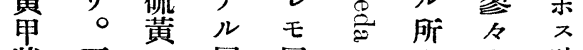

牀而分尿尿き ナ タ 硫

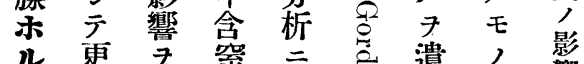

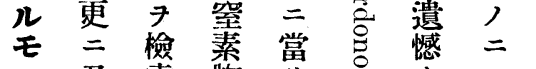

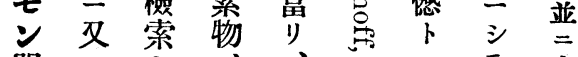

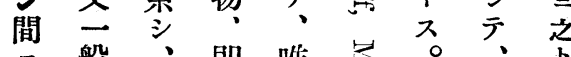

壬般之即唯 学即而

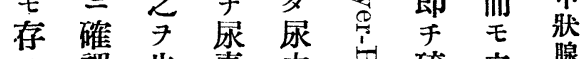

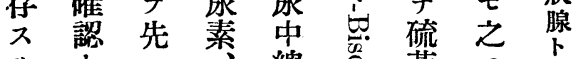

ル七こ系總总黄 こ

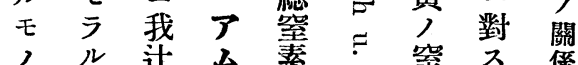

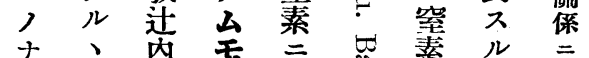

リガ科云就芯紊新イ就

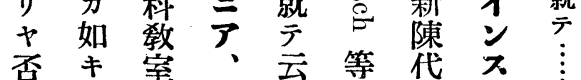

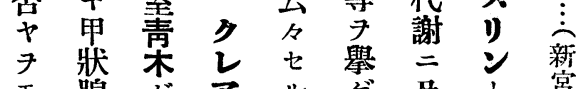

モ腺染方方及宫

併禾主手等ボ硫

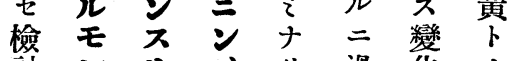

討

り1注し依ズ關關

ス 射

リ

ソリノ、各僅

, 得各本學嫼 ル

拮多 示驗当导,

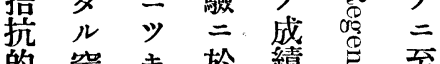

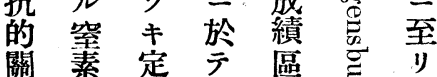

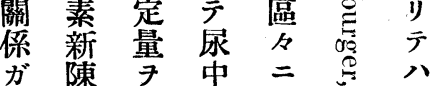




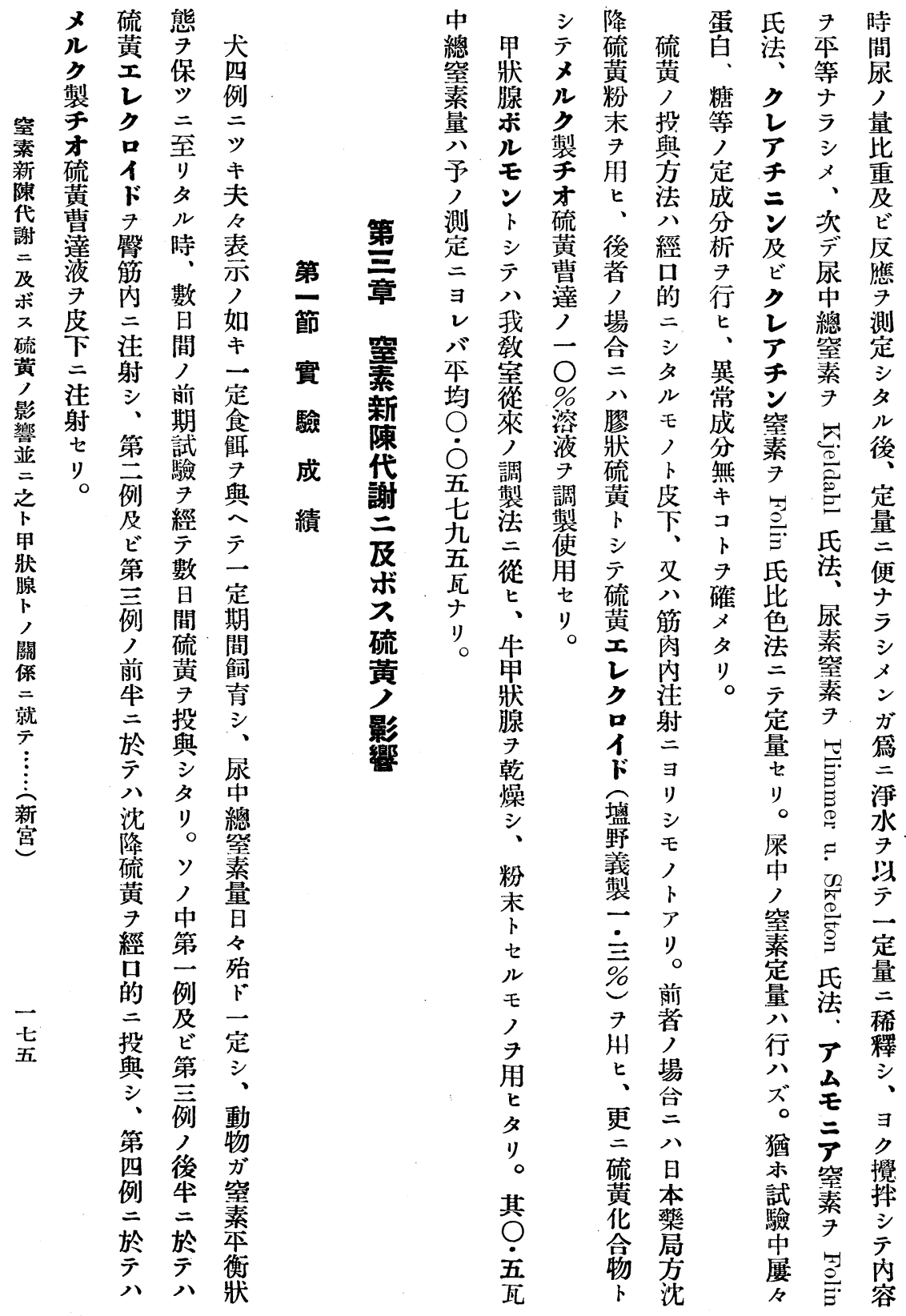



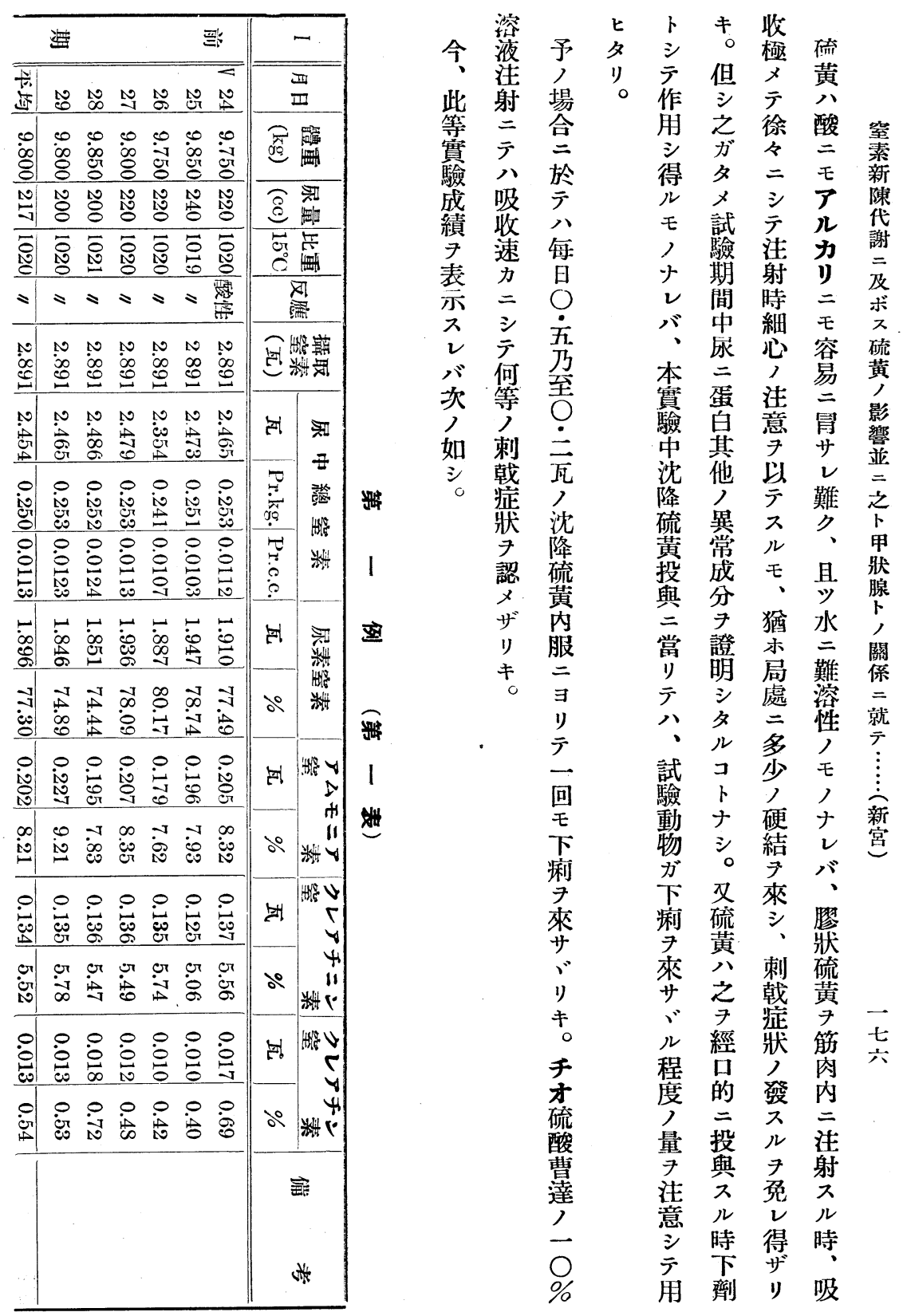


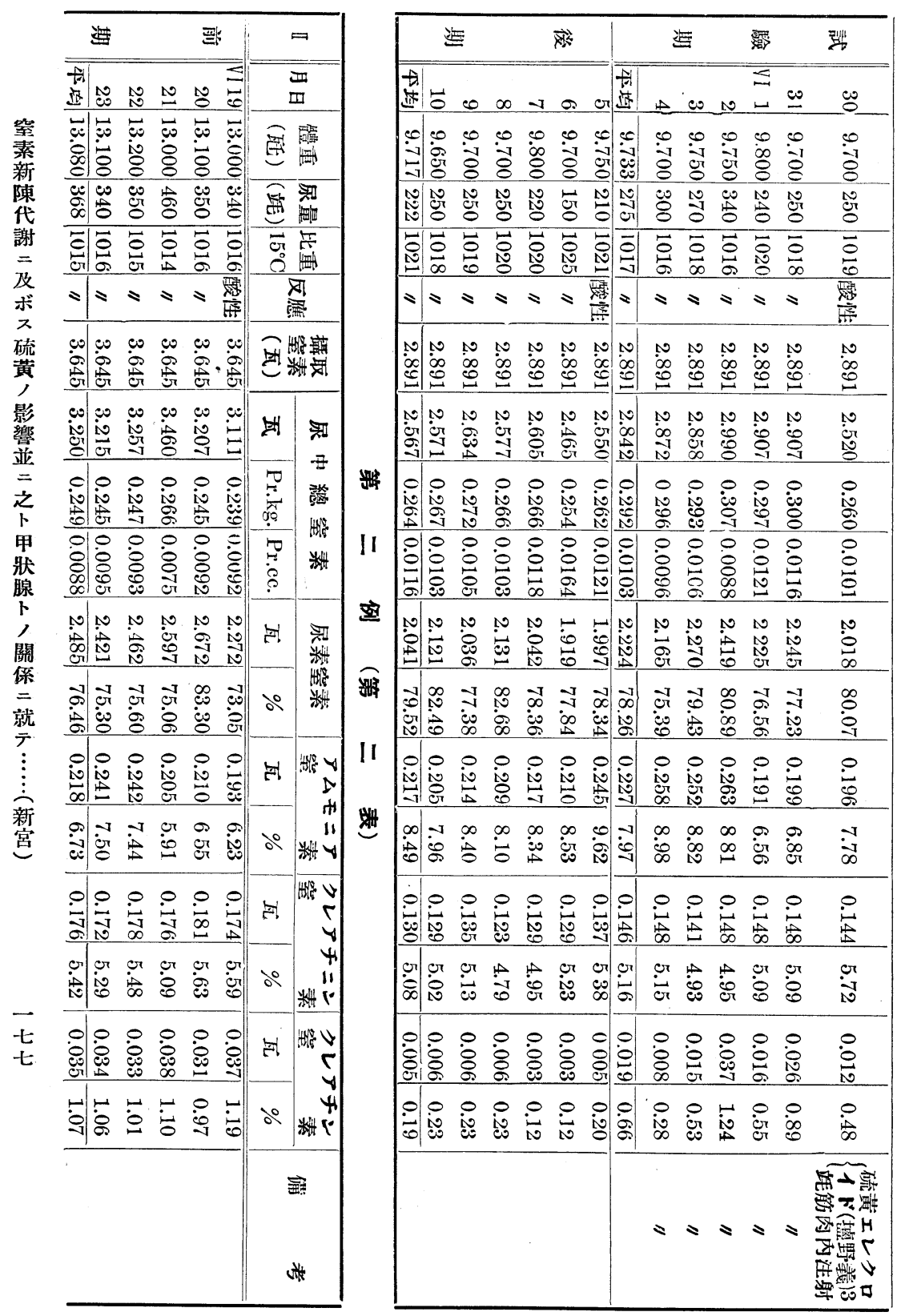




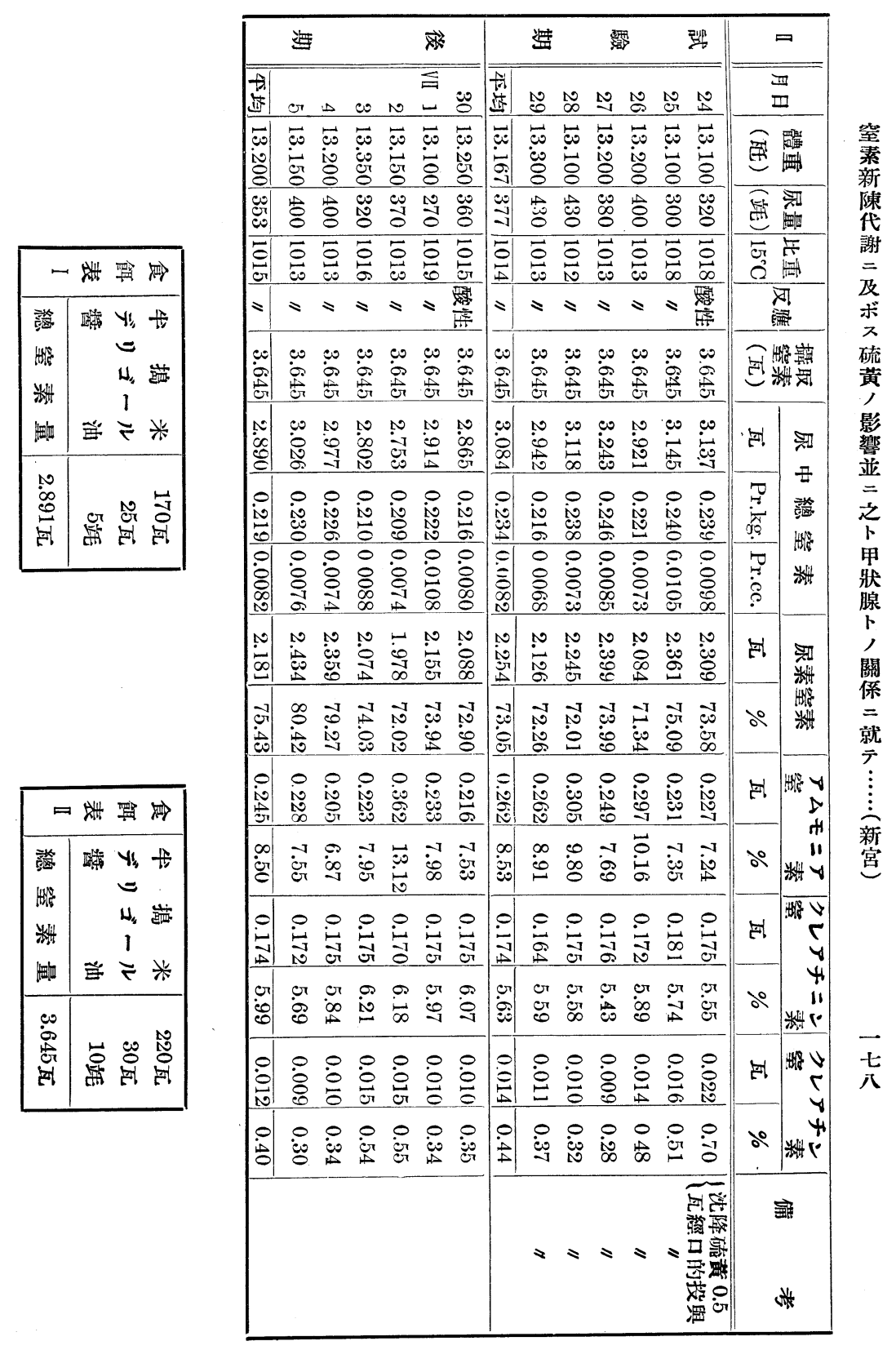




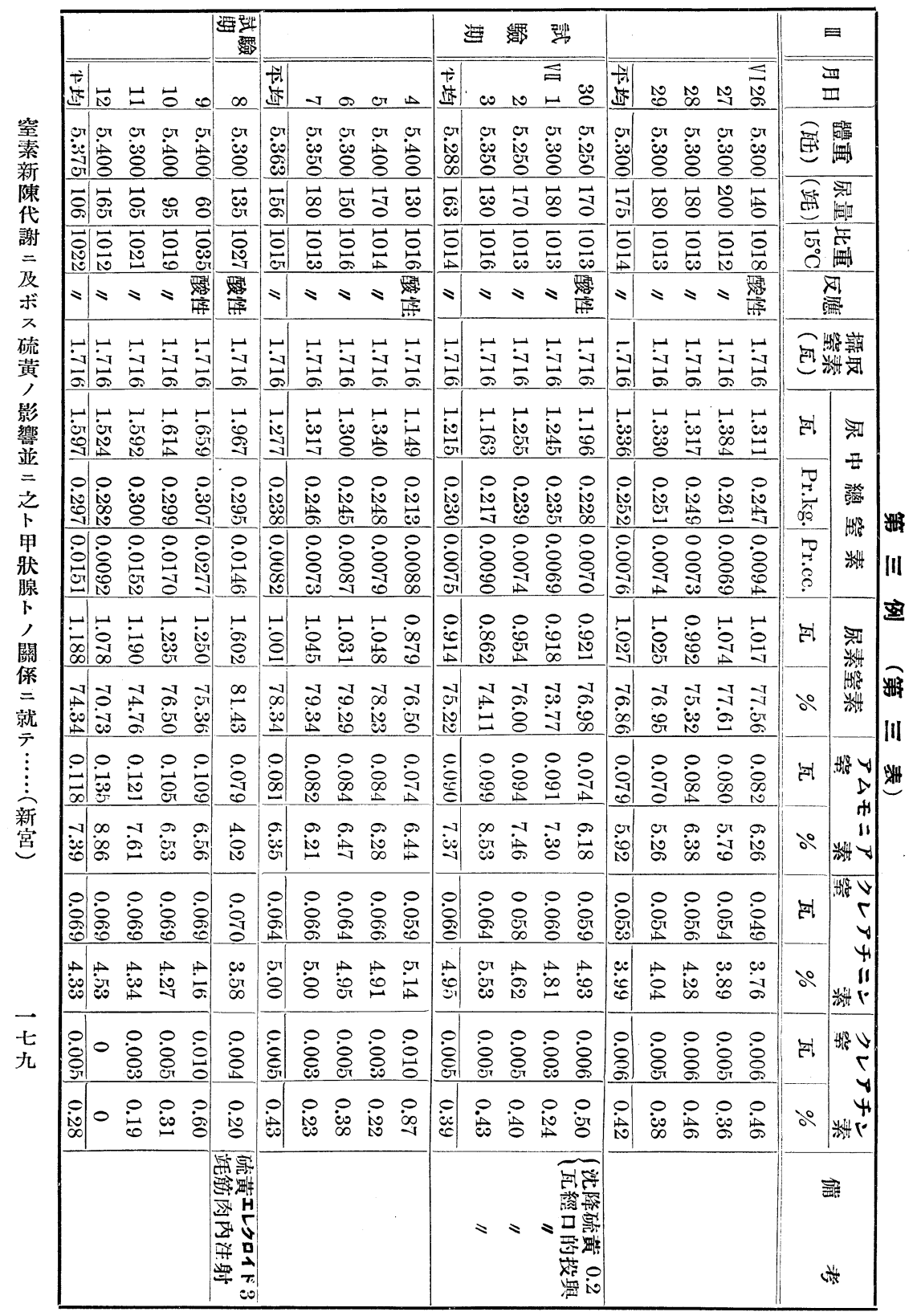




\begin{tabular}{|c|c|c|c|c|c|c|c|c|}
\hline \multicolumn{2}{|c|}{ 造 } & 砶 & 瑟 & \multicolumn{2}{|c|}{ 些 } & \multicolumn{2}{|r|}{ こ } & \\
\hline 蓸 & 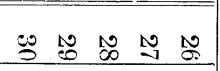 & 梌 & 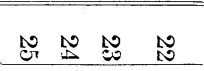 & 警 & 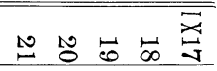 & \multicolumn{2}{|c|}{ 洜 } & \\
\hline 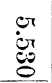 & 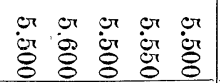 & 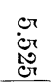 & 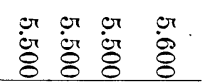 & 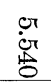 & 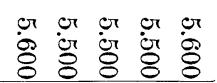 & \multicolumn{2}{|c|}{ 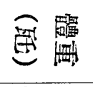 } & \\
\hline$\underset{\substack{\infty \\
\infty}}{\vec{D}}$ & 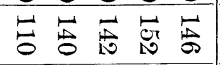 & $\vec{J}$ & 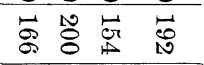 & $\stackrel{N}{\vec{H}}$ & $\checkmark)$ & \multicolumn{2}{|c|}{ 蛋洒 } & \\
\hline 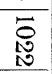 & 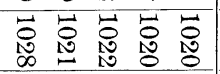 & 官 & 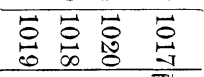 & 寄 & 居总总宫它 & \multicolumn{2}{|c|}{ जٓ 盇 } & \\
\hline 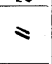 & 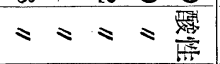 & $\approx$ & ミミs & $\approx$ & $s=s=\frac{d}{8}$ & \multicolumn{2}{|c|}{ 聇 } & \\
\hline 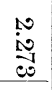 & 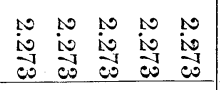 & $\begin{array}{l}\text { No } \\
\text { iv } \\
\text { iv } \\
\end{array}$ & 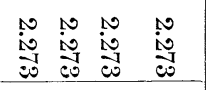 & iv & 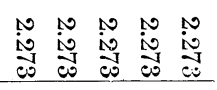 & \multicolumn{2}{|c|}{ 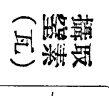 } & \\
\hline 荡 & 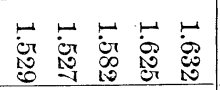 & 落 & 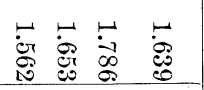 & $\begin{array}{l}\dot{0} \\
\dot{0} \\
\dot{0}\end{array}$ & 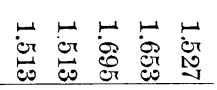 & 한 & \multirow{3}{*}{ 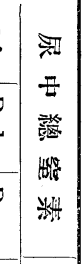 } & \\
\hline $\begin{array}{l}0 \\
\dot{0} \\
\text { o. } \\
0\end{array}$ & 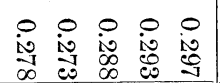 & $\begin{array}{l}0 \\
\dot{8}\end{array}$ & 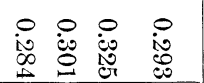 & 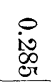 & 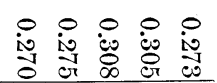 & 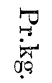 & & \\
\hline$\stackrel{\circ}{\stackrel{\circ}{\leftrightarrows}}$ & 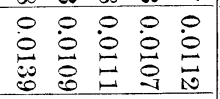 & $\begin{array}{l}\dot{0} \\
\dot{0} \\
\dot{0} \\
\dot{0}\end{array}$ & 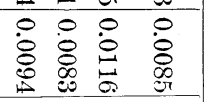 & : & 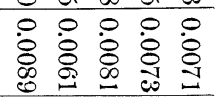 & ?ִ & & $\mathbb{E}$ \\
\hline $\overrightarrow{\dot{\hat{\theta}}}$ & 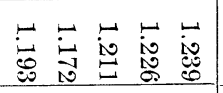 & 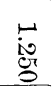 & 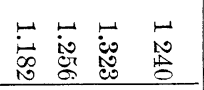 & $\begin{array}{l}\overrightarrow{0} \\
\stackrel{0}{0} \\
0 \\
0\end{array}$ & 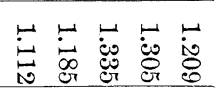 & 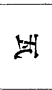 & \multirow{2}{*}{ 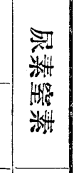 } & \\
\hline 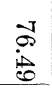 & 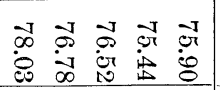 & ल] & 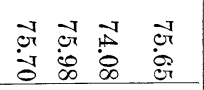 & ì & 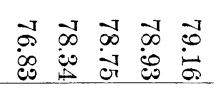 & よீ & & \\
\hline$\stackrel{\circ}{\stackrel{0}{0}}$ & 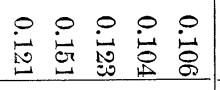 & $\stackrel{\dot{8}}{8}$ & 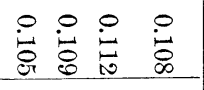 & : & $\begin{array}{l}\circ \\
\dot{0} \\
\dot{0} \\
8\end{array}$ & 자 & \multirow[t]{2}{*}{ 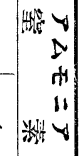 } & 浀 \\
\hline 공 & 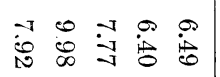 & $\underset{\dot{\theta}}{\dot{\rho g}}$ & 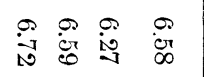 & $\ddot{\theta}$ & 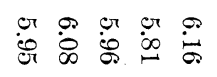 & よீ & & \\
\hline $\begin{array}{l}0 \\
0 \\
0 \\
0 .\end{array}$ & 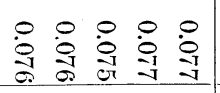 & \begin{tabular}{l}
0 \\
$\dot{9}$ \\
\cline { 1 - 1 } \\
\end{tabular} & $\begin{array}{lll}\circ & 0 & 0 \\
0 & 0 & 0 \\
0 & 0 & 0 \\
1 & 0 & 0\end{array}$ & $\begin{array}{l}0 \\
\dot{0} \\
01\end{array}$ & 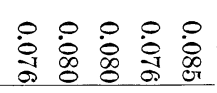 & 에 & \multirow{2}{*}{$\mid \begin{array}{rr}5 \\
y \\
y \\
y \\
11 \\
* 4\end{array}$} & \\
\hline$\stackrel{+\infty}{\infty}$ & 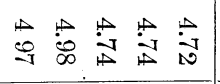 & $\stackrel{\leftrightarrow}{\infty}$ & 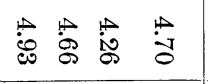 & $\ddot{8}$ & 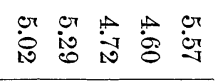 & do & & \\
\hline$\stackrel{8}{8}$ & 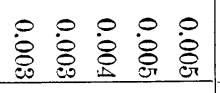 & : & 号总总 & : & 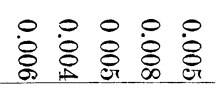 & 언 & $\left|\begin{array}{rl}4 & y \\
- & y\end{array}\right|$ & \\
\hline \multirow[t]{2}{*}{$\underset{i}{i}$} & 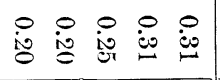 & $\stackrel{0}{\infty}$ & 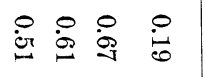 & $\stackrel{\infty}{\infty}_{\infty}$ & 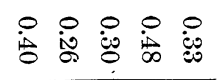 & \multicolumn{2}{|c|}{ 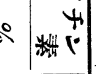 } & \\
\hline & & & 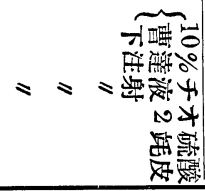 & & & & 㖊 & \\
\hline
\end{tabular}




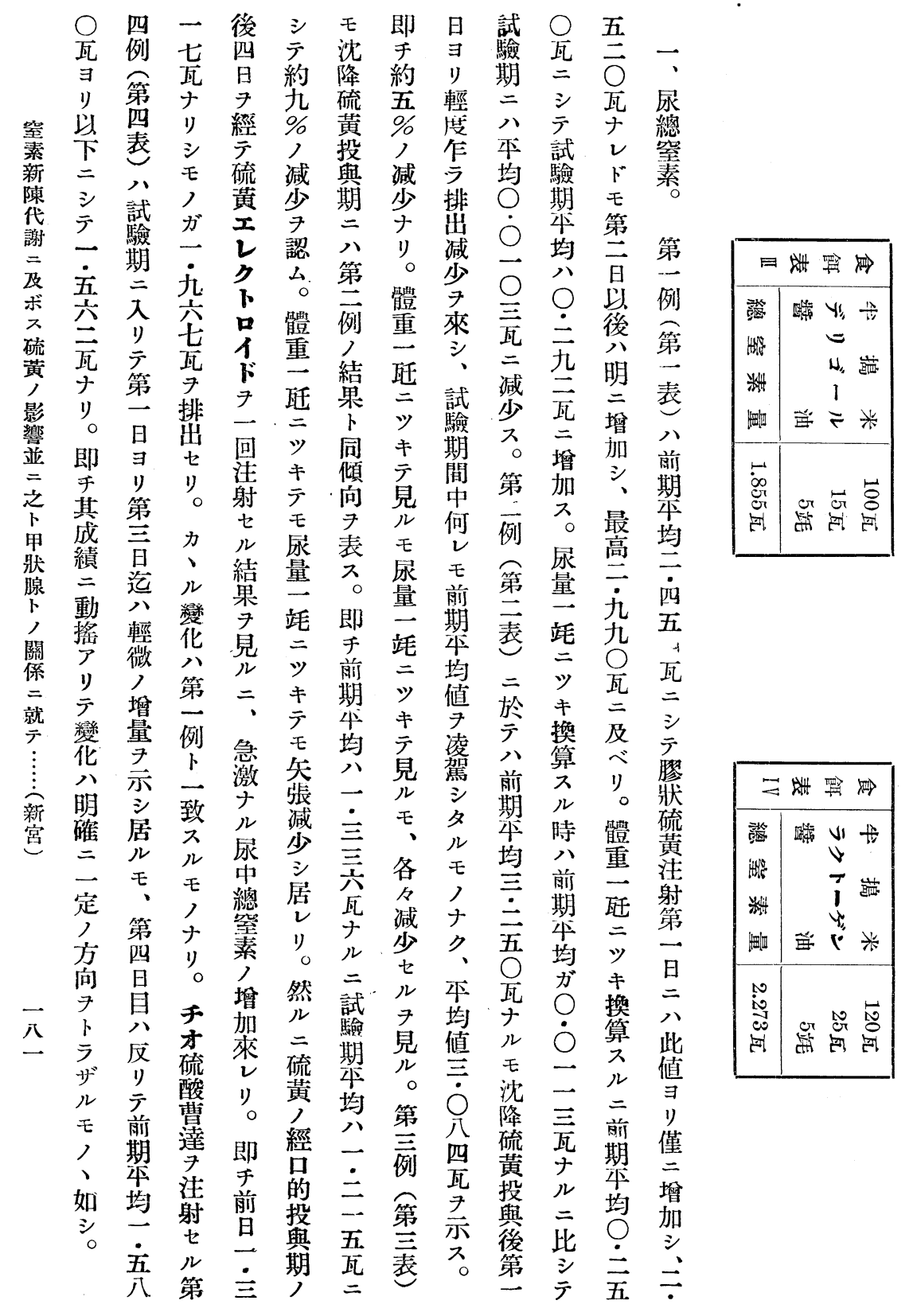




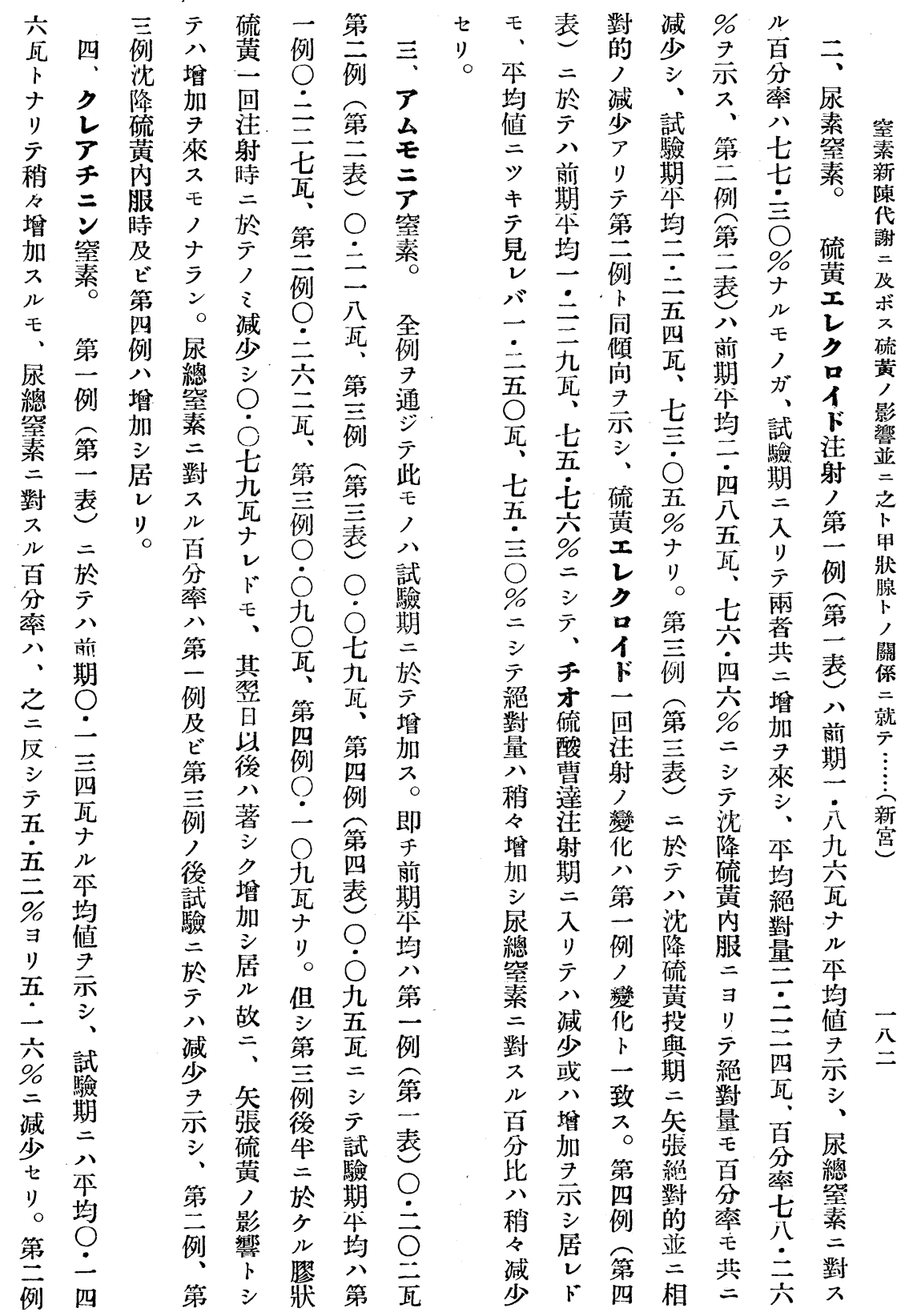




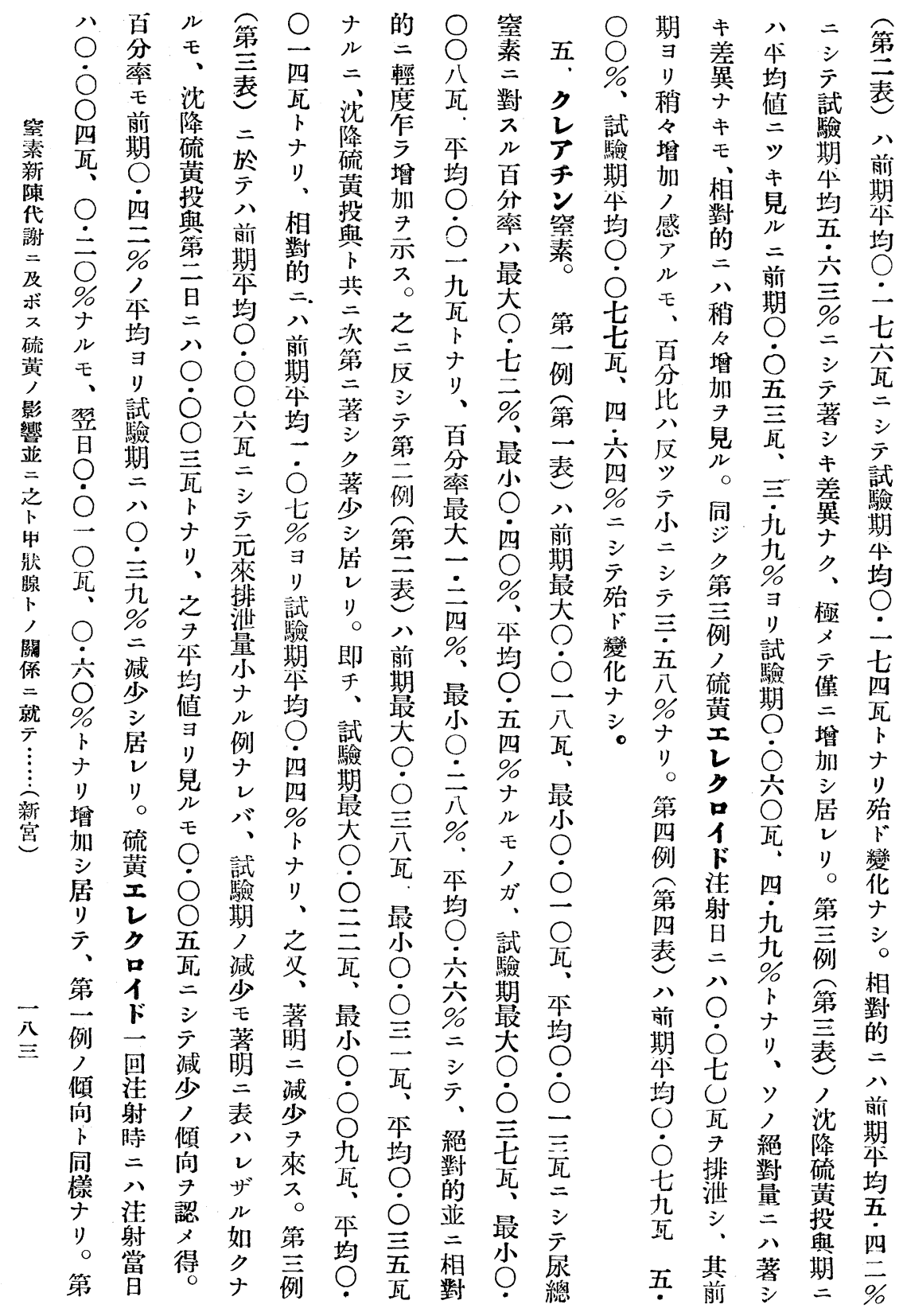



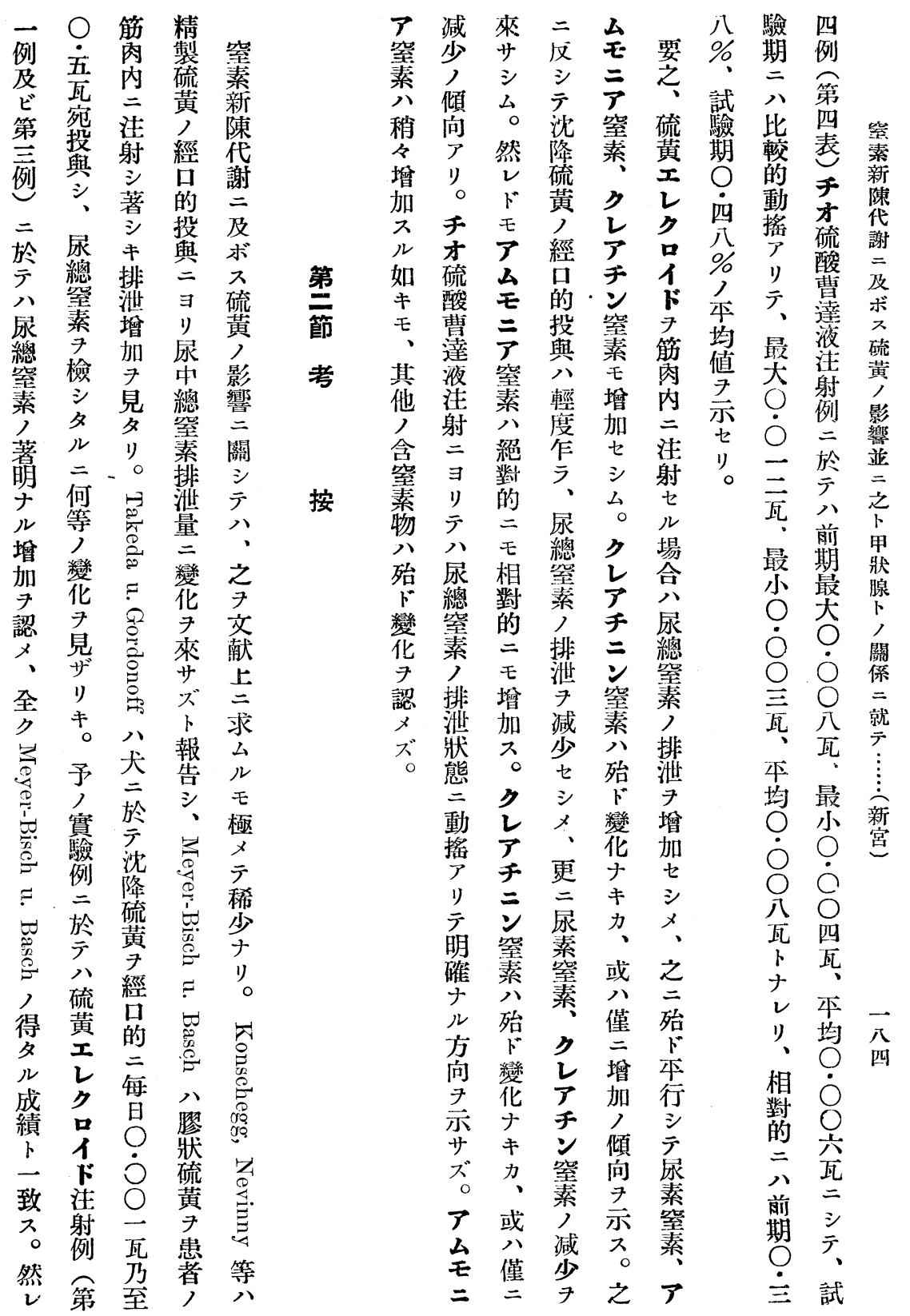


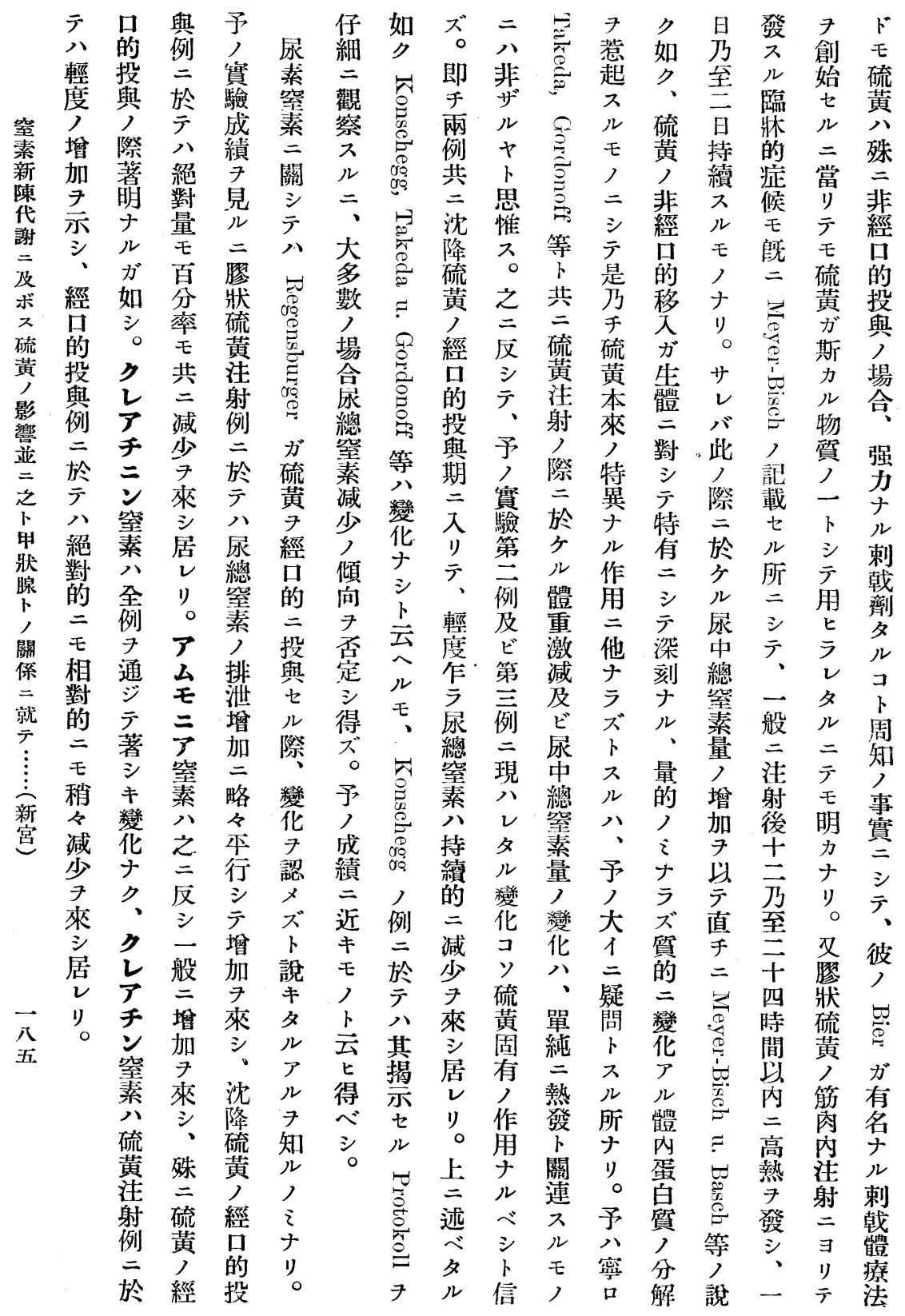




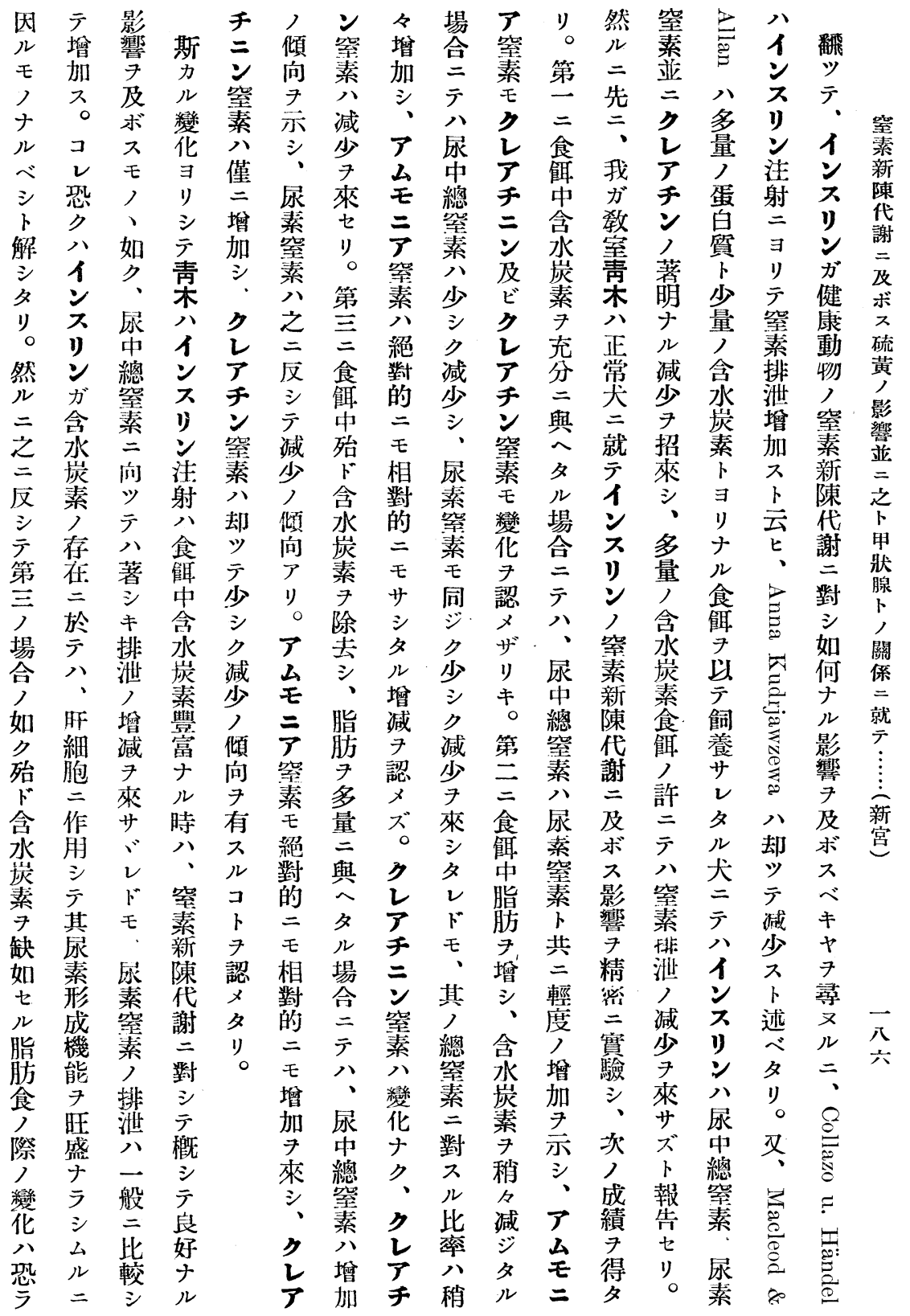




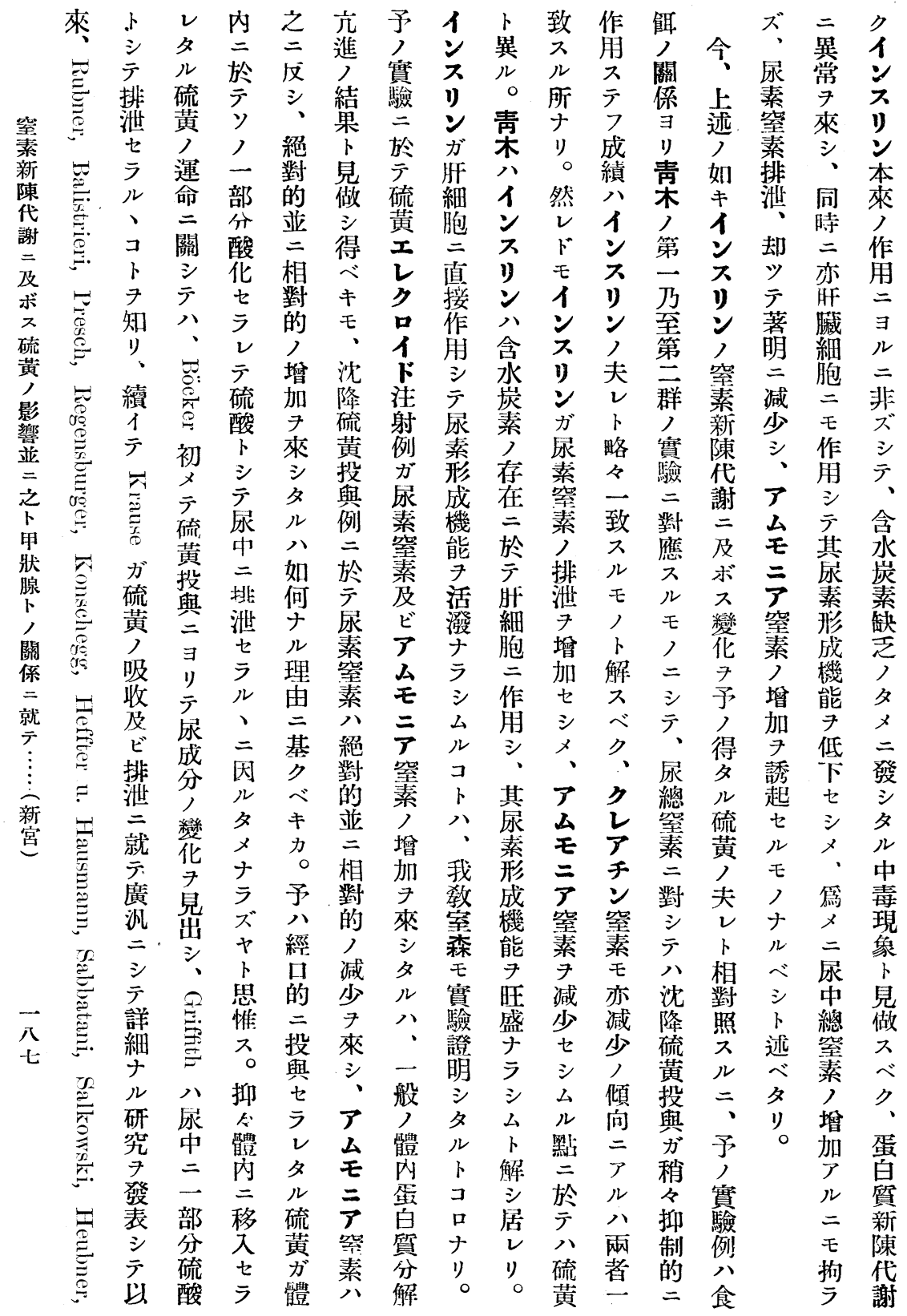




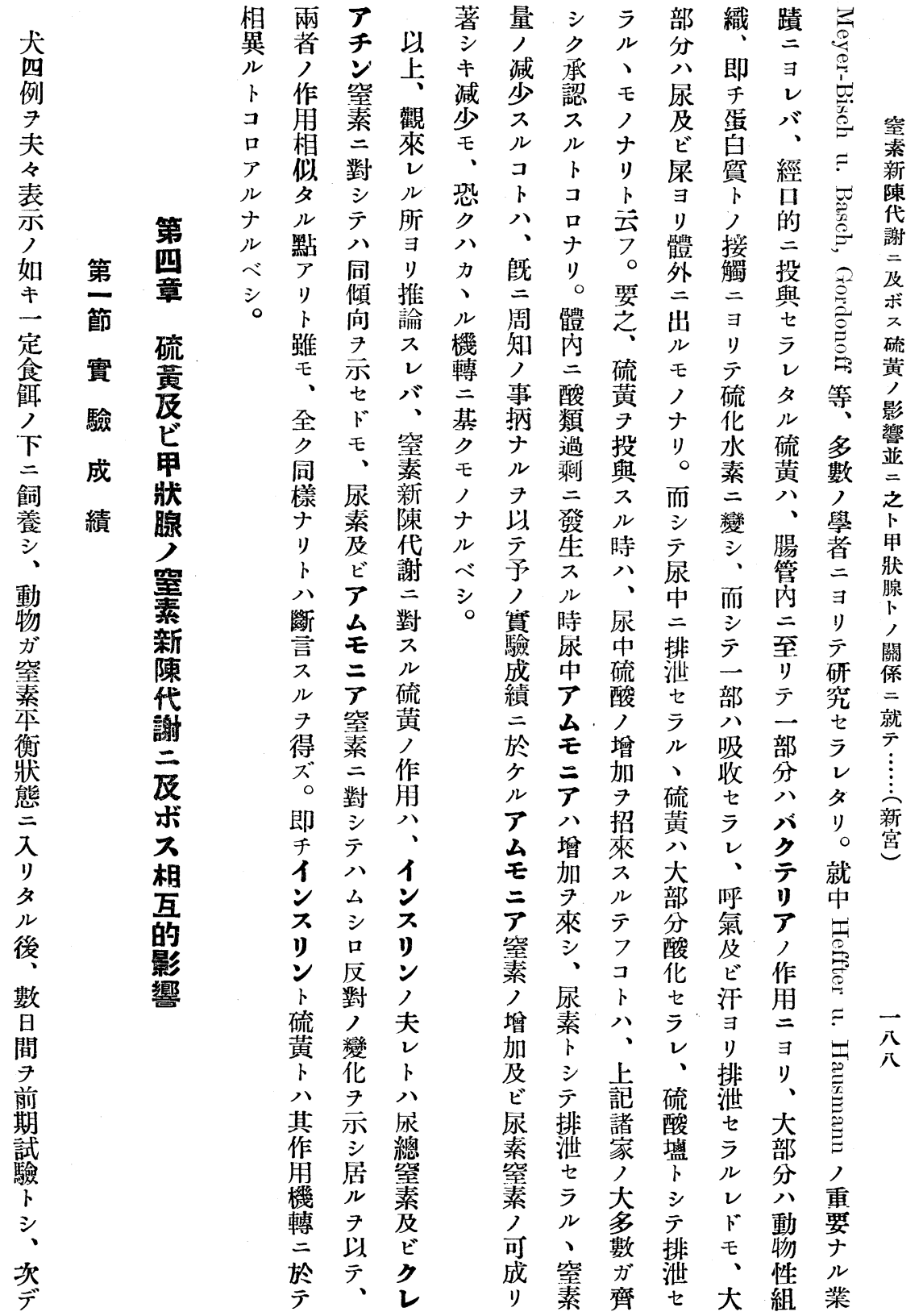



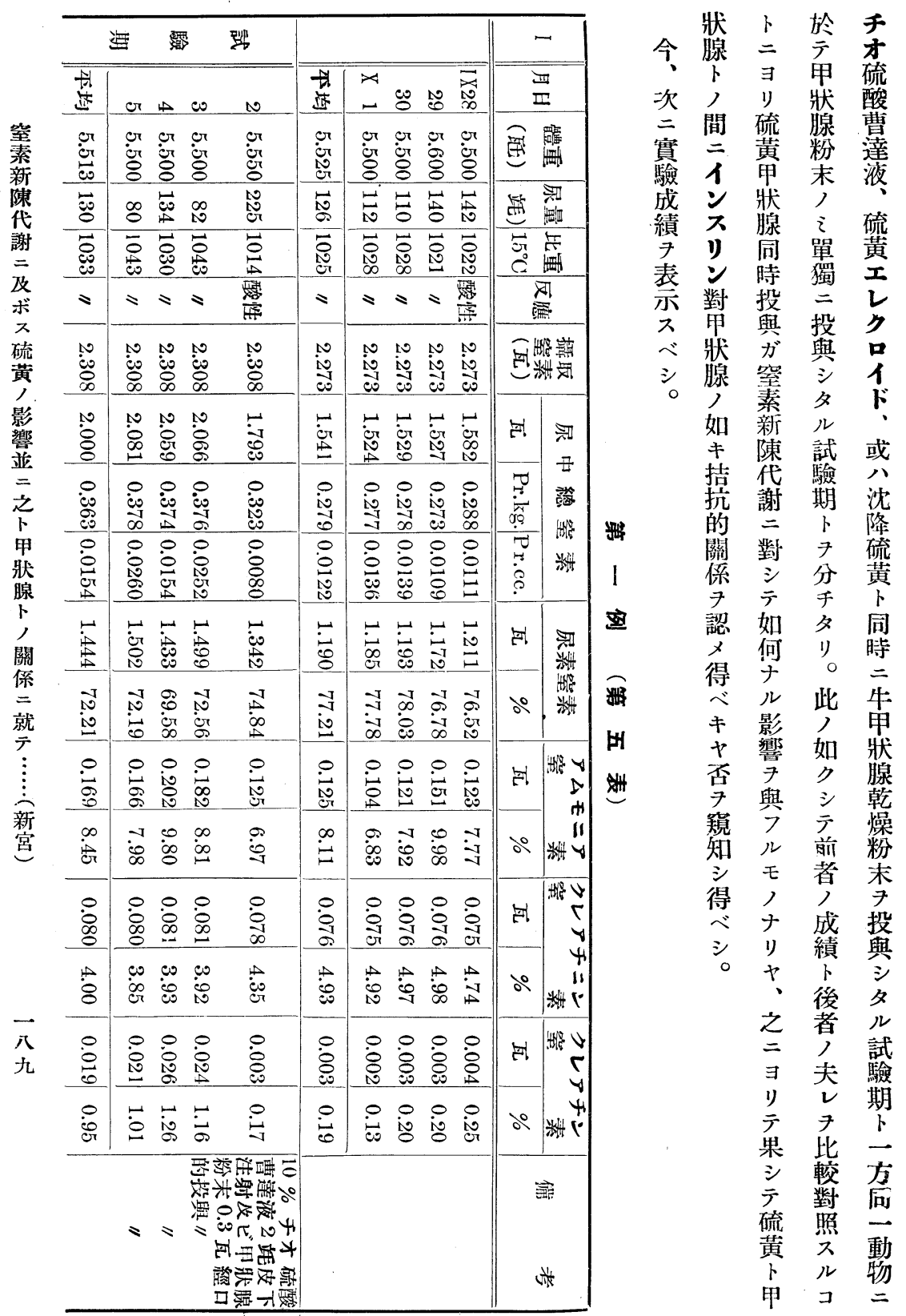


\begin{tabular}{|c|c|c|c|}
\hline & 尊霜 & & \\
\hline 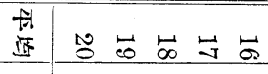 & 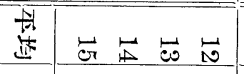 & 意 & 垔 \\
\hline 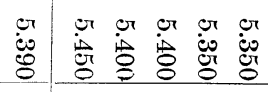 & 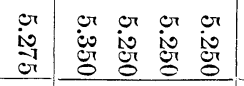 & 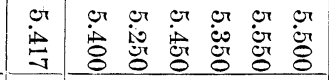 & 駧暨 \\
\hline 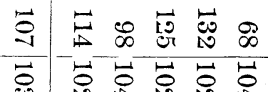 & 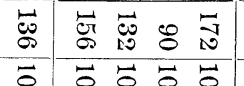 & 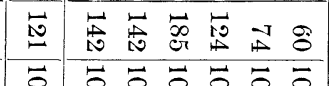 & 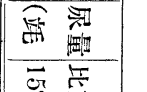 \\
\hline 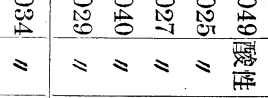 & 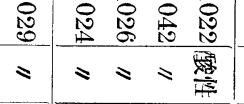 & 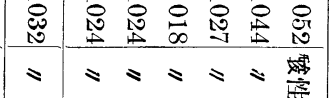 & 然等 \\
\hline 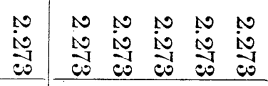 & 思 & 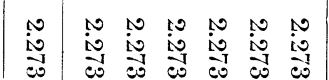 & 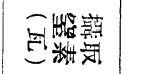 \\
\hline 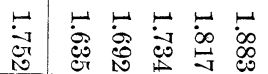 & 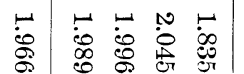 & 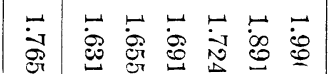 & $\because \approx$ \\
\hline 善 & 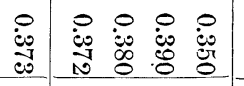 & 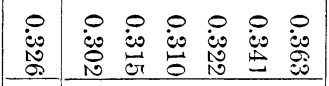 & 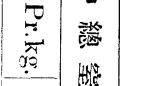 \\
\hline 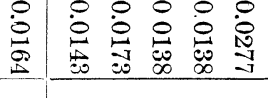 & 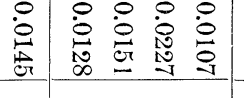 & 鄫总总总 & 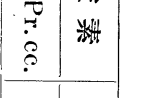 \\
\hline 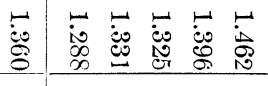 & 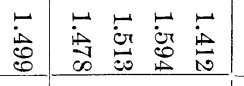 & 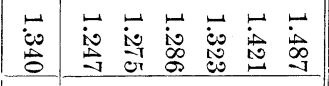 & 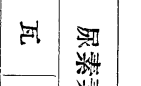 \\
\hline 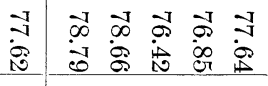 & 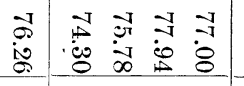 & 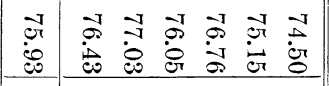 & $\therefore 7$ \\
\hline 恶 & 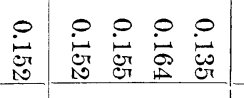 & 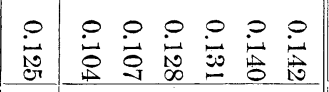 & $\Rightarrow$ of \\
\hline 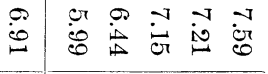 & 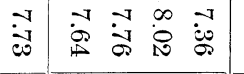 & 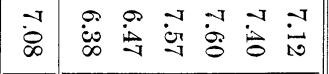 & $\therefore x^{4}$ \\
\hline 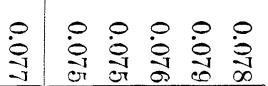 & 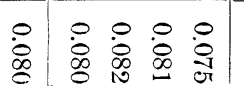 & 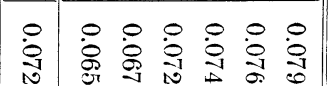 & 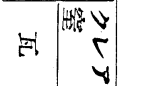 \\
\hline 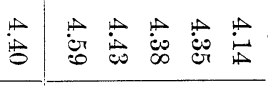 & 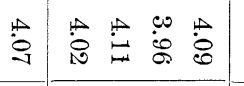 & 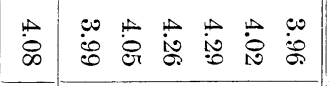 & $\therefore \underbrace{4 * 4: 4}$ \\
\hline 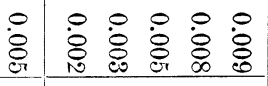 & 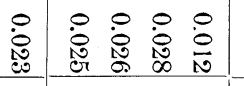 & 엽. & 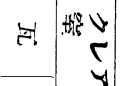 \\
\hline 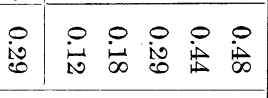 & 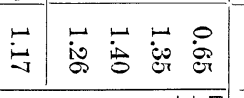 & 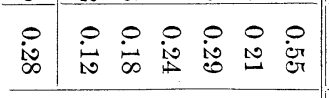 & $\therefore \begin{array}{cc}4 \\
x_{*}^{*}\end{array}$ \\
\hline & & & \\
\hline
\end{tabular}




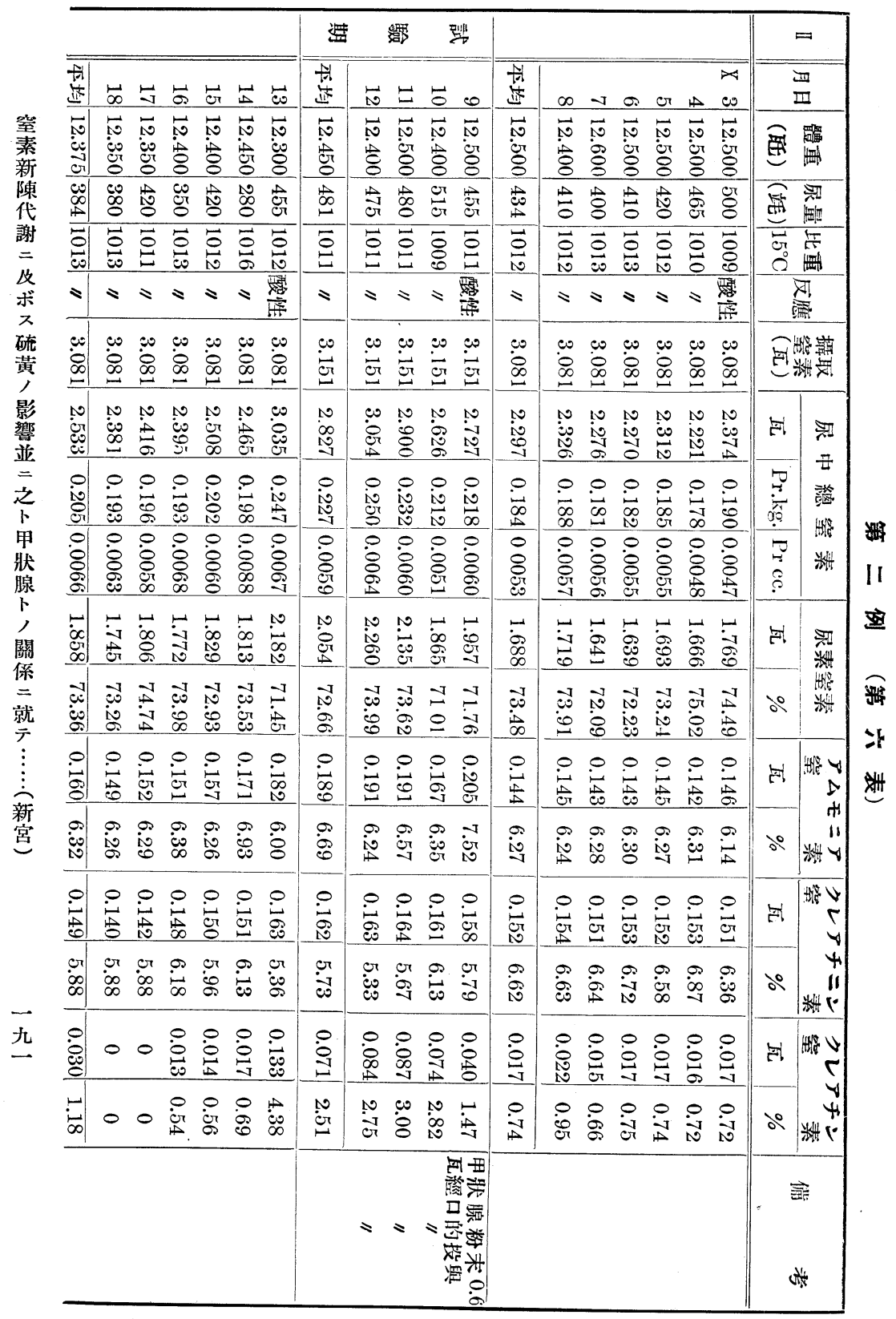




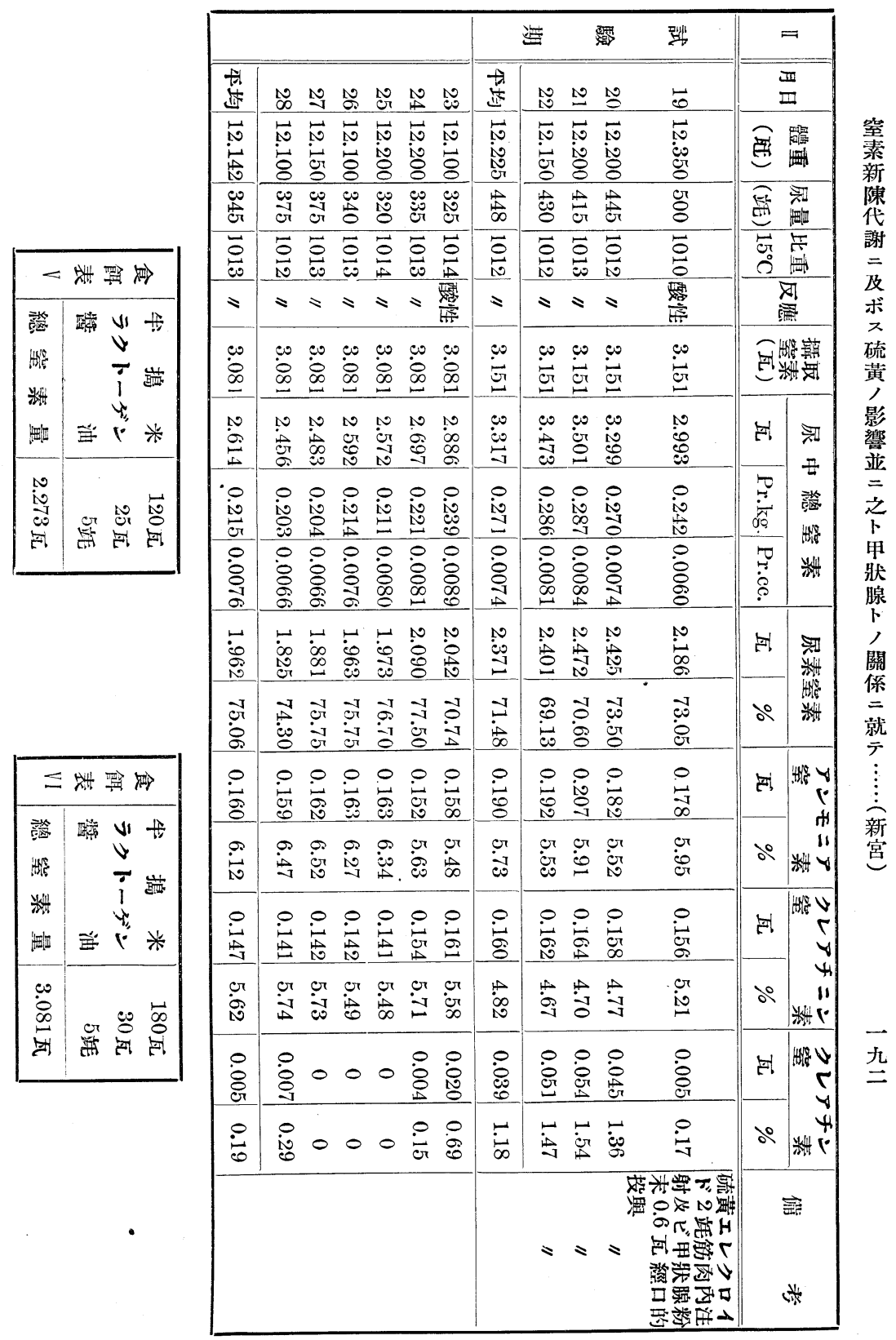




\begin{tabular}{|c|c|c|c|c|c|c|c|}
\hline & \multicolumn{2}{|c|}{ 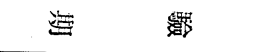 } & 譬 & \multirow[b]{2}{*}{ 柲 } & \multirow[b]{2}{*}{$\vec{v} \sqsupseteq \vec{b} \infty \infty^{\vec{a}}$} & \multirow{2}{*}{\multicolumn{2}{|c|}{$\begin{array}{l}\text { 目 } \\
\text { 而 }\end{array}$}} \\
\hline 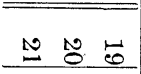 & 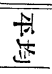 & $\vec{\infty} \vec{d} \vec{\sigma} \vec{c} \vec{t} \vec{b}$ & $\breve{\omega}$ & & & & \\
\hline 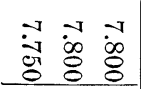 & iv & 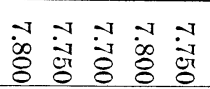 & के & \begin{tabular}{c}
-1 \\
$\infty$ \\
\cline { 1 - 1 }
\end{tabular} & 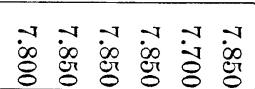 & \multicolumn{2}{|c|}{ 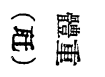 } \\
\hline 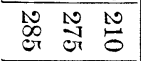 & $\stackrel{1}{\infty}$ & 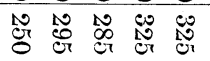 & 总 & 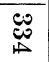 & 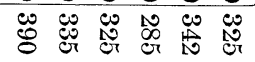 & \multicolumn{2}{|c|}{ 洒 } \\
\hline 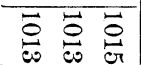 & $\overrightarrow{\stackrel{\vec{c}}{c}}$ & $\overrightarrow{0} \overrightarrow{0} \overrightarrow{0} \overrightarrow{0}$ & $\vec{\rho}$ & $\overrightarrow{\overrightarrow{0}}$ & $\vec{\circ} \vec{\circ} \overrightarrow{0} \overrightarrow{0} \overrightarrow{0} \overrightarrow{0}$ & \multicolumn{2}{|c|}{ 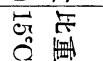 } \\
\hline 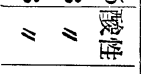 & $s$ & $s=8 s$ & 整 & $s$ & 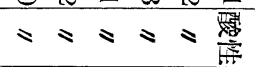 & \multicolumn{2}{|c|}{ 酒 } \\
\hline 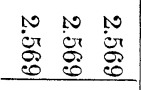 & 产 & $\begin{array}{lllll}10 & 0 & 0 & 0 & 0 \\
0 & 0 & 0 & 0 \\
0\end{array}$ & :o & 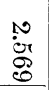 & 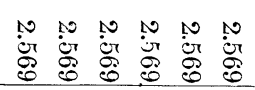 & \multicolumn{2}{|c|}{ 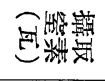 } \\
\hline 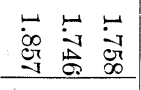 & 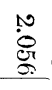 & 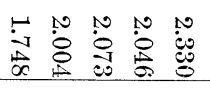 & 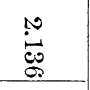 & 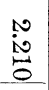 & 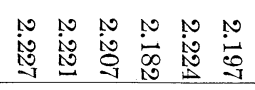 & \multirow{3}{*}{\multicolumn{2}{|c|}{ 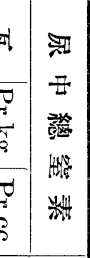 }} \\
\hline 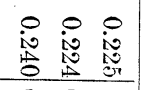 & 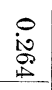 & 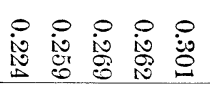 & $\begin{array}{l}0 \\
\text { io } \\
\text { N } \\
\text { D }\end{array}$ & $\begin{array}{l}0 \\
\dot{\infty} \\
\dot{\infty} \\
\dot{\infty}\end{array}$ & 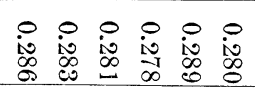 & & \\
\hline 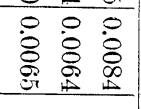 & $\dot{8}$ & 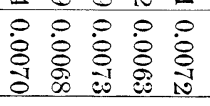 & $\begin{array}{l}0 \\
\dot{0} \\
-1 \\
0\end{array}$ & $\stackrel{8}{\circ}$ & 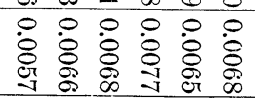 & & \\
\hline 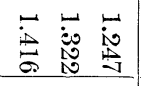 & 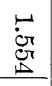 & 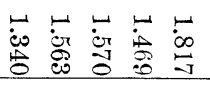 & 它 & $\vec{\circ}$ & 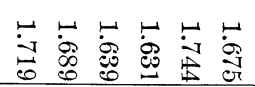 & 배난 & \multirow{2}{*}{ 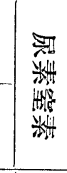 } \\
\hline 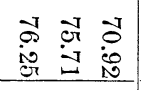 & 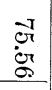 & 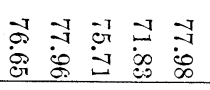 & 誌 & के & 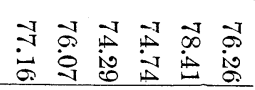 & de & \\
\hline 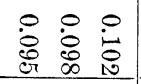 & $\stackrel{\circ}{\stackrel{c}{c}}$ & 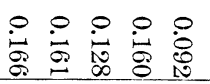 & 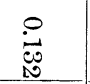 & $\dot{0}$ & 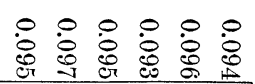 & 엄 & 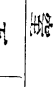 \\
\hline 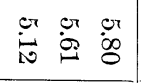 & 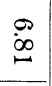 & 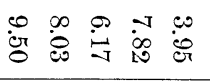 & $\dot{\infty}$ & $\stackrel{4}{\dot{\dot{\theta}}}$ & 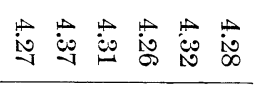 & \multicolumn{2}{|c|}{20 料 } \\
\hline $\begin{array}{lll}0 & 0 & 0 \\
\dot{\infty} & \dot{0} & \dot{0} \\
0 & 0 & 0 \\
\end{array}$ & $\begin{array}{l}8 \\
\dot{\infty} \\
\infty \\
\infty\end{array}$ & 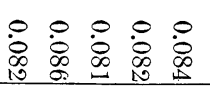 & 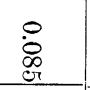 & $\begin{array}{l}\stackrel{0}{\infty} \\
\dot{\infty} \\
\infty\end{array}$ & 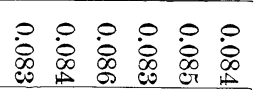 & 안 & \multirow{2}{*}{ 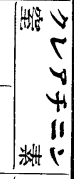 } \\
\hline 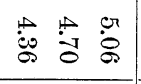 & $\begin{array}{l}\dot{1} \\
\dot{1} \\
\end{array}$ & 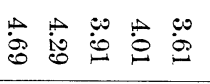 & 电 & $\begin{array}{l}0 \\
\dot{0}\end{array}$ & 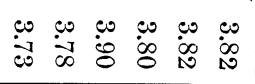 & $\therefore$ & \\
\hline 总 & 号 & 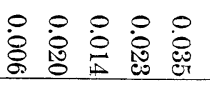 & : & $\dot{8}$ & : & $ㅂ ㅏ ㄴ$ & 48 \\
\hline \multirow[t]{2}{*}{$\begin{array}{lll}i & 0 & 0\end{array}$} & $\begin{array}{l}\circ \\
\substack{\infty \\
c} \\
\infty\end{array}$ & 甶 & : & 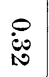 & 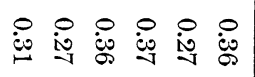 & \multicolumn{2}{|c|}{$\therefore$ 䊉 } \\
\hline & & $=8$ & 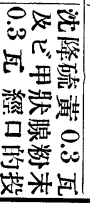 & & $\theta^{\circ}$ & & 䁹 \\
\hline
\end{tabular}




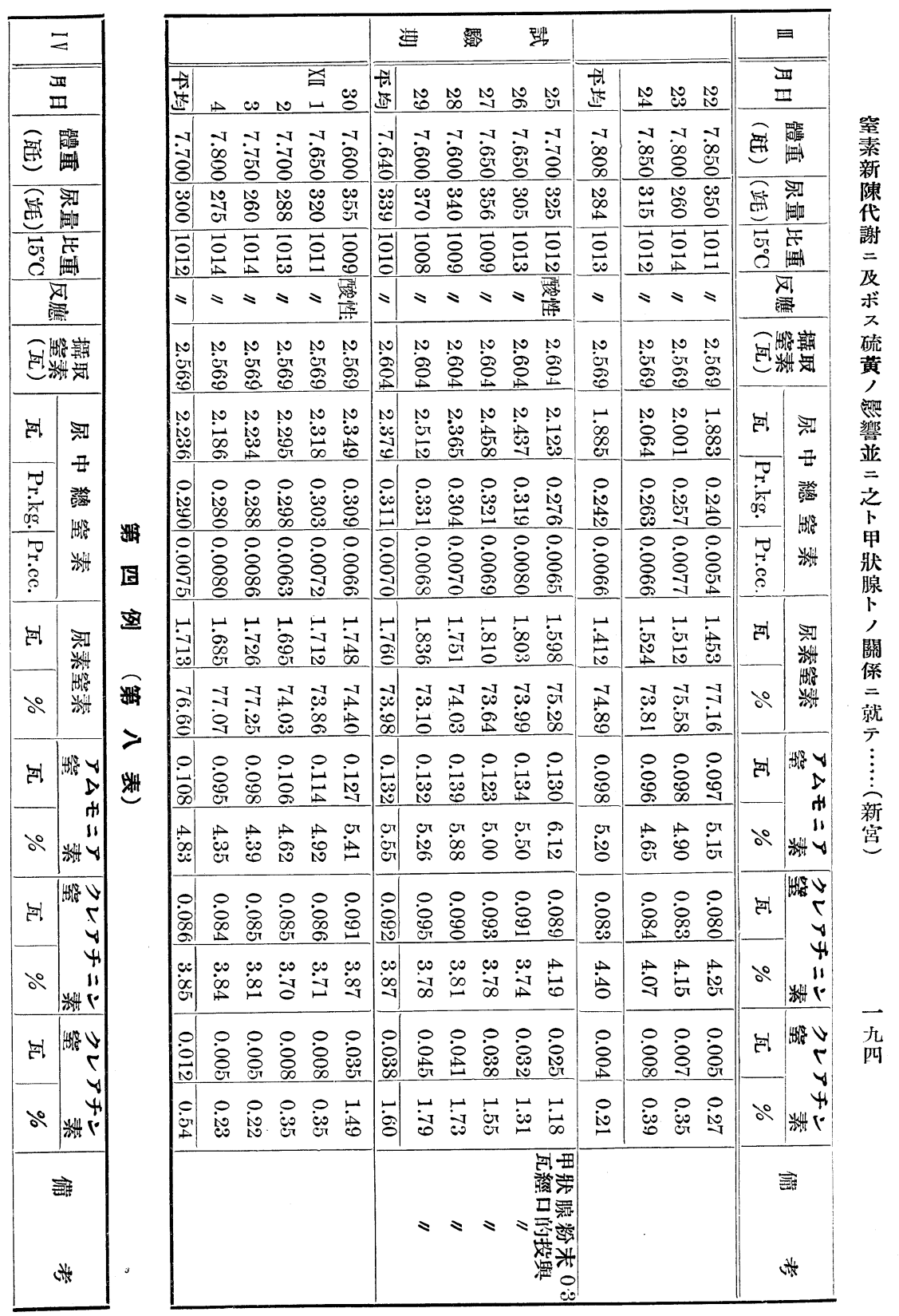




\begin{tabular}{|c|c|c|c|c|c|c|}
\hline & & & 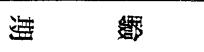 & 些 & & \\
\hline 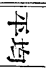 & 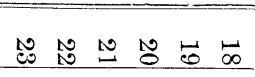 & 苦 & $\exists \vec{\sigma} \vec{\sigma} \vec{\Delta} \overrightarrow{0}$ & $\vec{n}$ & 热 & $\exists \Delta+\infty-\frac{\pi}{0}$ \\
\hline 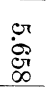 & 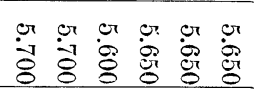 & 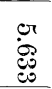 & 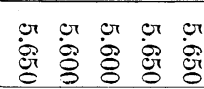 & بَ & 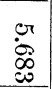 & 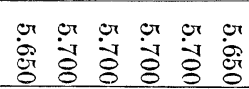 \\
\hline 通 & 缡 & $\stackrel{\mathbb{N}}{\stackrel{N}{G}}$ & : & $\ddot{8}$ & $\begin{array}{l}10 \\
\infty \\
\infty\end{array}$ & 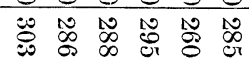 \\
\hline $\overrightarrow{\bar{\omega}}$ & 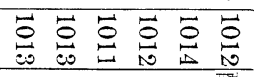 & $\stackrel{5}{10}$ & 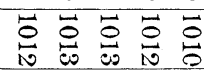 & 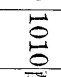 & 官 & 总总宫宫总宫 \\
\hline$\leqslant$ & $s \leqslant s \leqslant s$ 霍 & $\leqslant$ & $s \leqslant s=8$ & 垔 & $=$ & 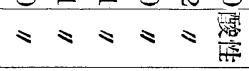 \\
\hline חֶ & 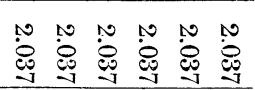 & 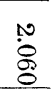 & $\begin{array}{lllll}0 & 0 & 0 & 0 & 0 \\
8 & 8 & 8 & 8 & 8 \\
8 & 8 & 8 & 8\end{array}$ & $\begin{array}{l}\stackrel{1}{\circ} \\
\dot{8}\end{array}$ & 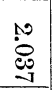 & 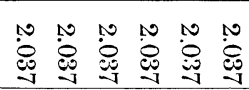 \\
\hline 范 & 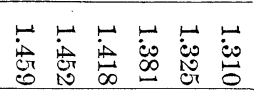 & $\begin{array}{c}+ \\
\dot{+} \\
\infty \\
\infty \\
\end{array}$ & 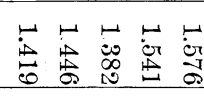 & $\vec{j}$ & $\begin{array}{l}\vec{A} \\
\stackrel{\vec{A}}{0} \\
\end{array}$ & 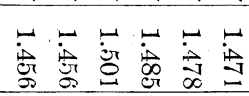 \\
\hline $\begin{array}{l}0 \\
\text { is } \\
\text { 点 }\end{array}$ & 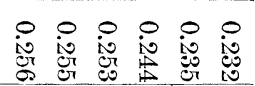 & 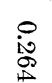 & 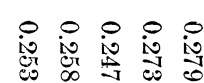 & Pि & : & 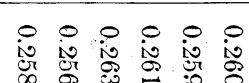 \\
\hline$\stackrel{0}{8}$ & $\begin{array}{l}\circ \\
\dot{8} \\
\dot{8}\end{array}$ & : & 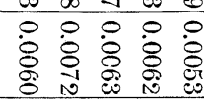 & 总 & $\begin{array}{l}0 \\
8 \\
\dot{8} \\
\text { ch } \\
1\end{array}$ & 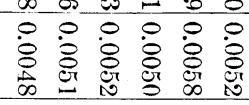 \\
\hline 宸 & 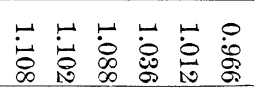 & 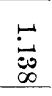 & 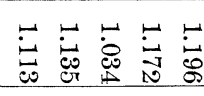 & $\stackrel{\vec{s}}{\vec{y}}$ & 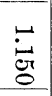 & 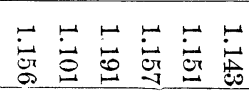 \\
\hline نَّ & 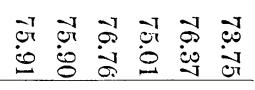 & $\begin{array}{l}\text { नै } \\
\dot{0} \\
\dot{\alpha}\end{array}$ & 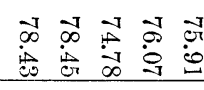 & 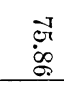 & $\begin{array}{l}-1 \\
-1 \\
8\end{array}$ & 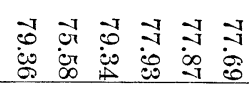 \\
\hline : & 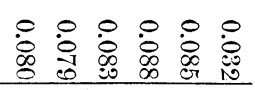 & $\stackrel{P}{\dot{E}}$ & 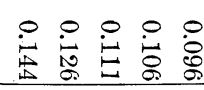 & $\dot{\ddot{g}}$ & : & $\begin{array}{l}0 \\
\dot{0} \\
0\end{array}$ \\
\hline or & 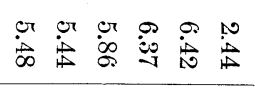 & $\ddot{\overrightarrow{9}}$ & 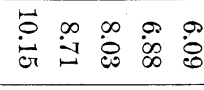 & $\dot{\theta}$ & $\underset{\mathrm{v}}{\mathrm{v}}$ & 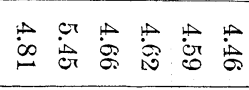 \\
\hline 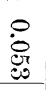 & 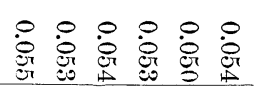 & : & 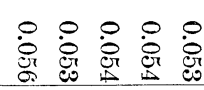 & 兽 & 䆥 & 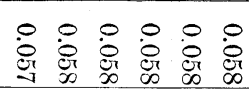 \\
\hline $\begin{array}{l}\infty \\
\infty \\
\infty\end{array}$ & 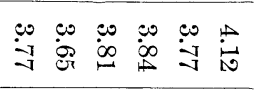 & 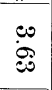 & 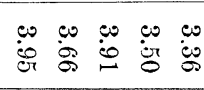 & 峞 & 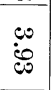 & 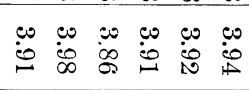 \\
\hline$\stackrel{8}{\circ}$ & 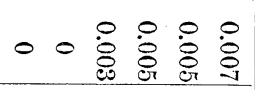 & 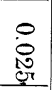 & $\begin{array}{l}\dot{0} \\
\dot{0} \\
0\end{array}$ & : & $\stackrel{\circ}{\dot{9}}$ & 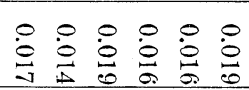 \\
\hline : & 00 i $\begin{array}{c}0 \\
\dot{0}\end{array}$ & $\overrightarrow{\dot{\infty}}$ & 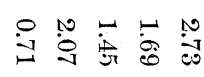 & $\stackrel{\oplus}{\oplus}$ & $\stackrel{\vec{G}}{\vec{G}}$ & 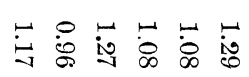 \\
\hline . & & & $s=s$ & 喼 & & \\
\hline
\end{tabular}




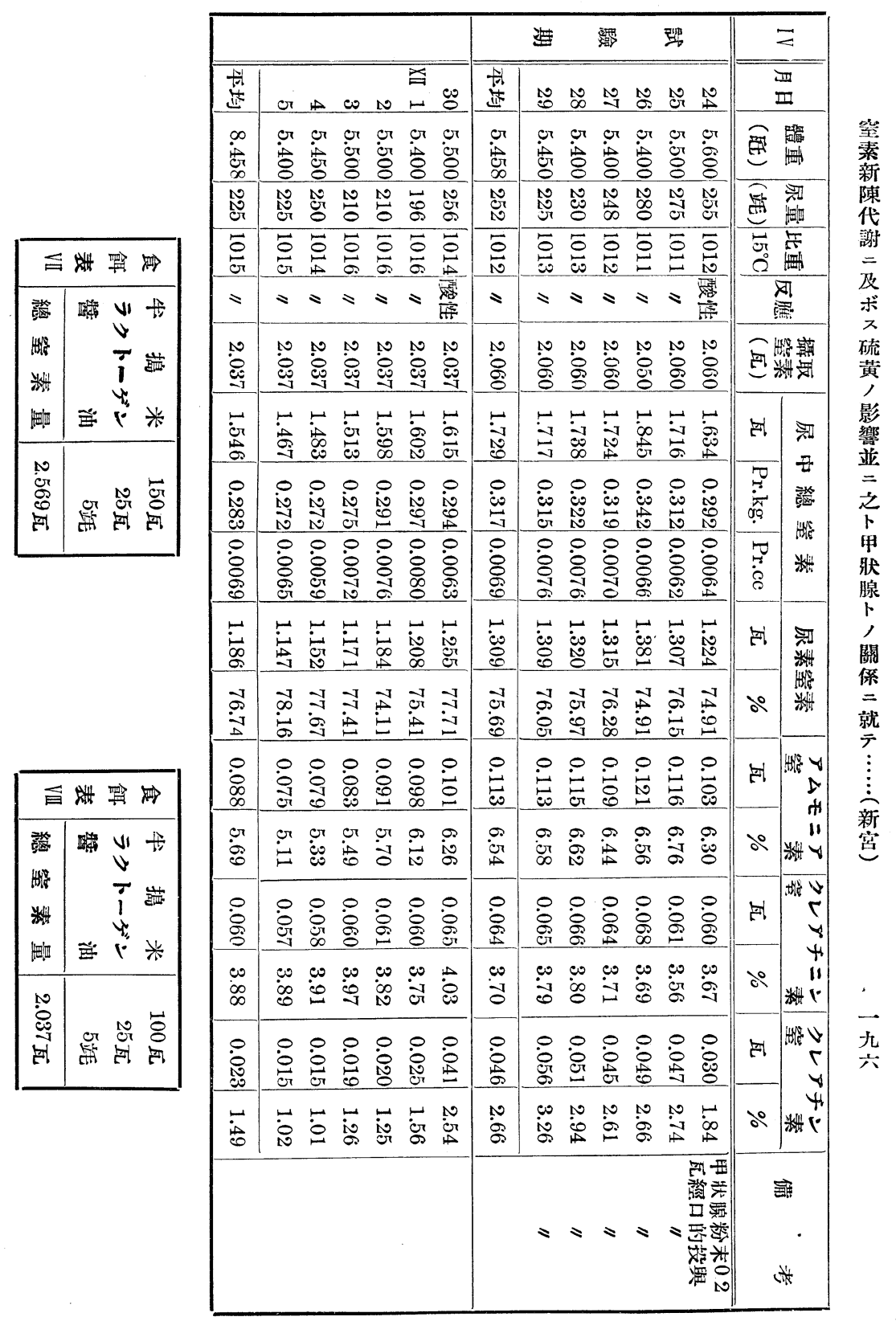




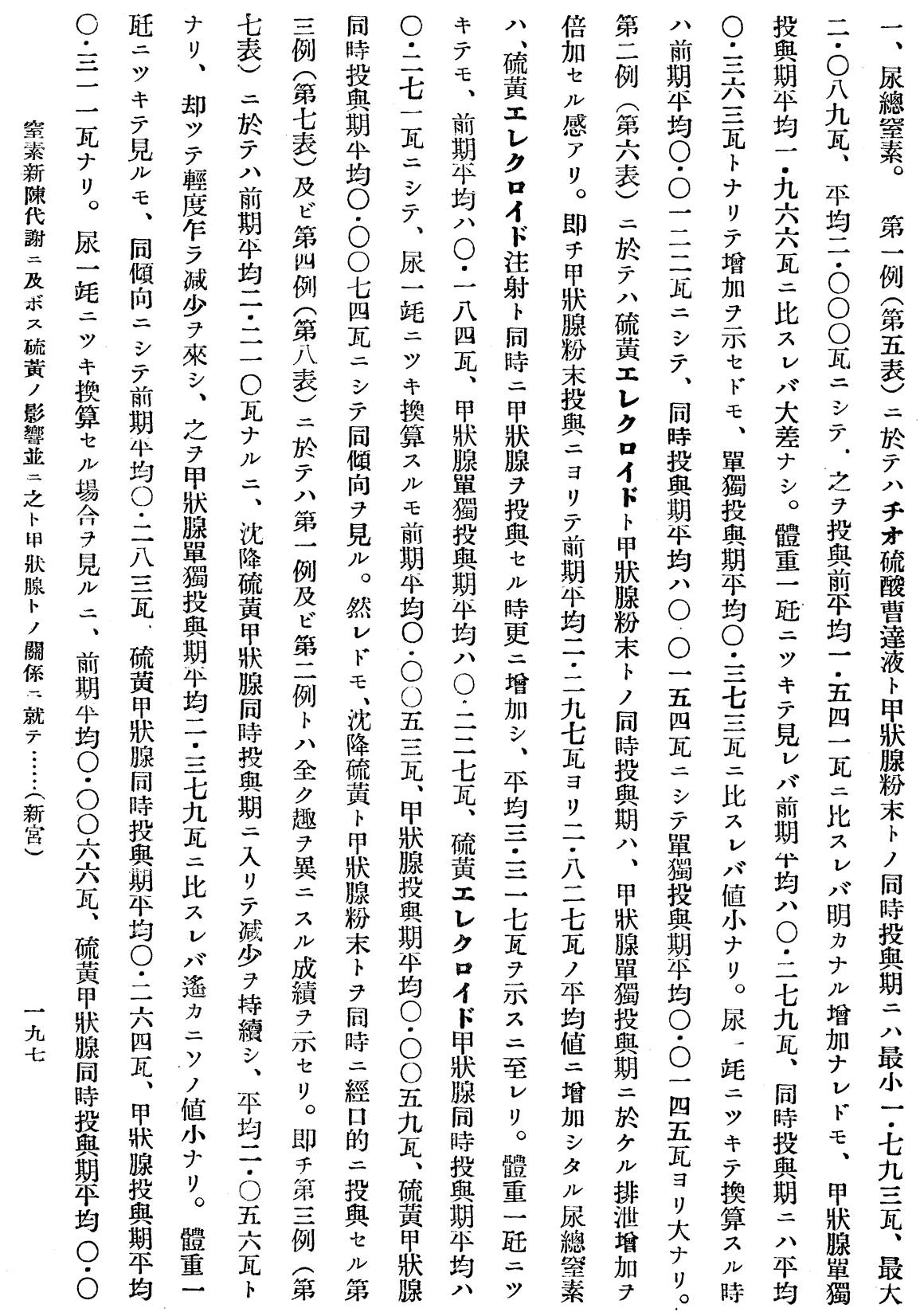




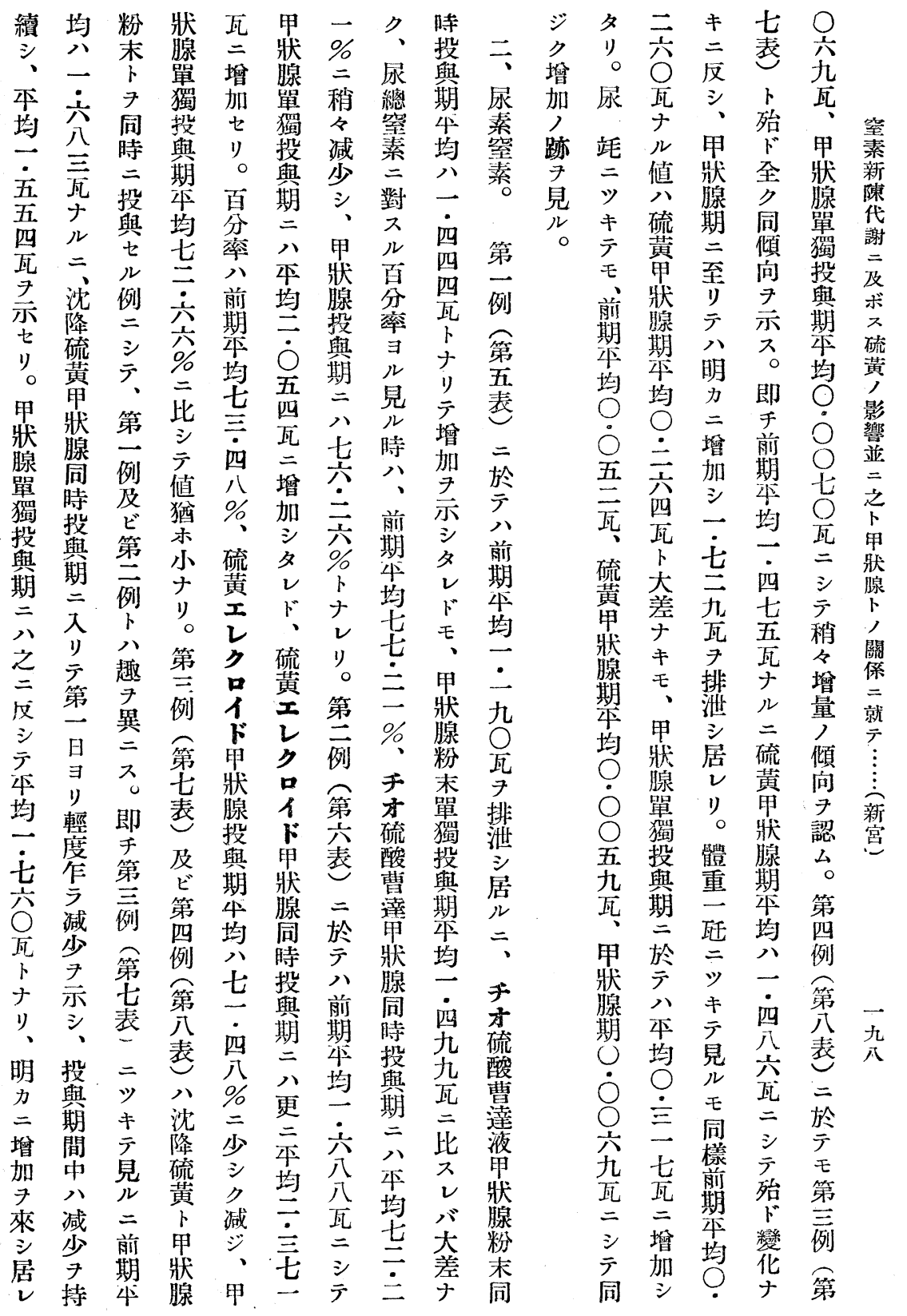




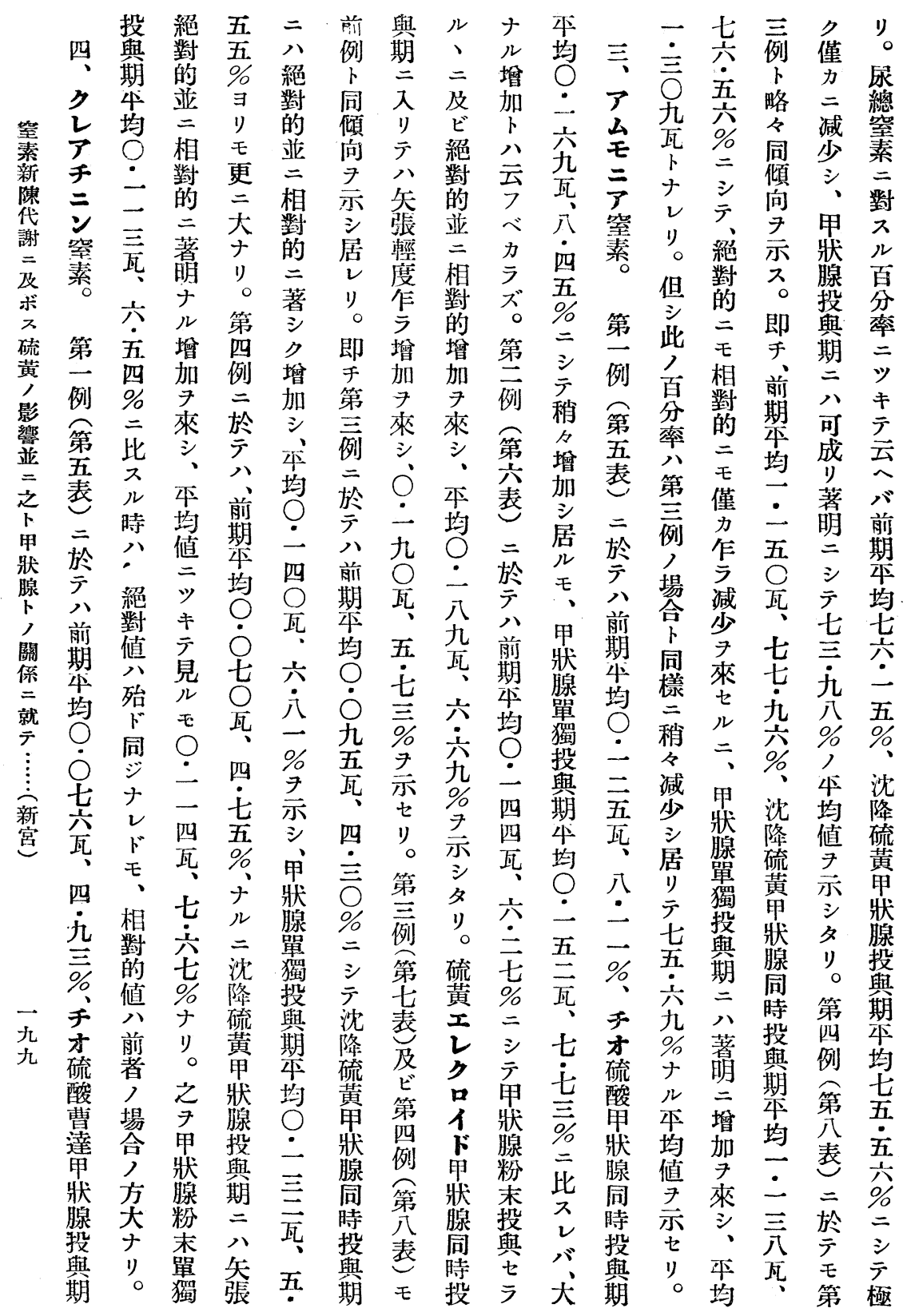




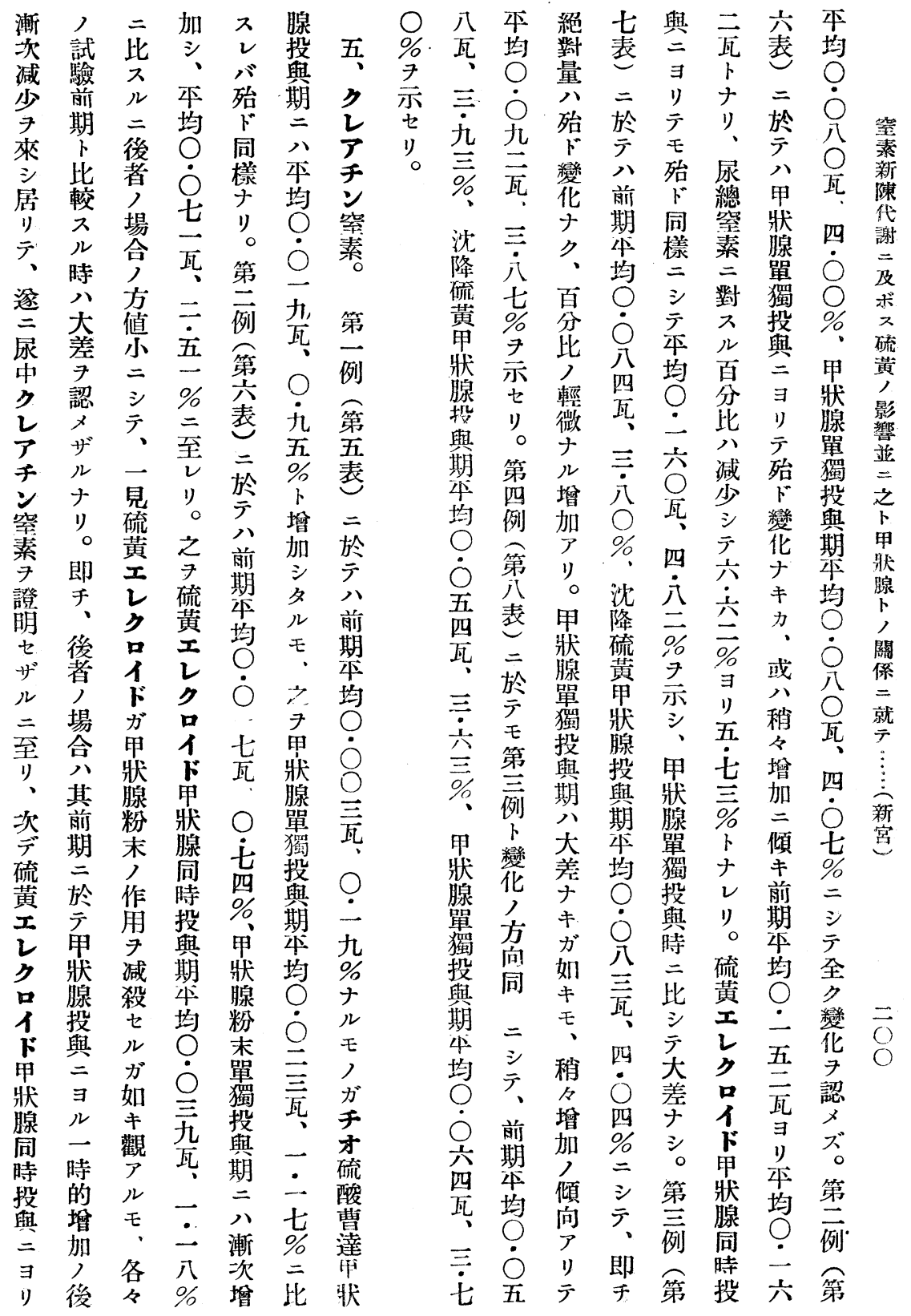




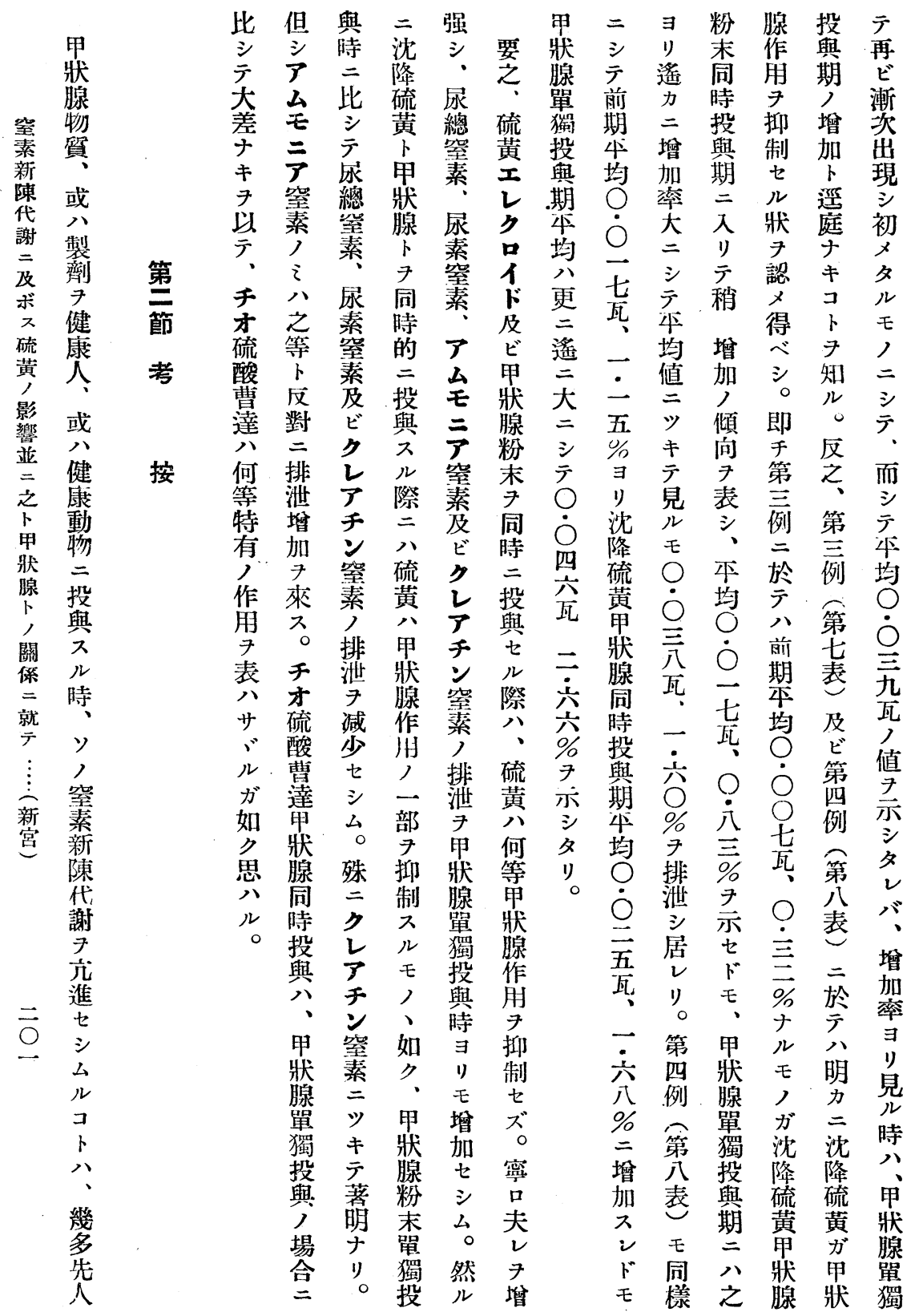




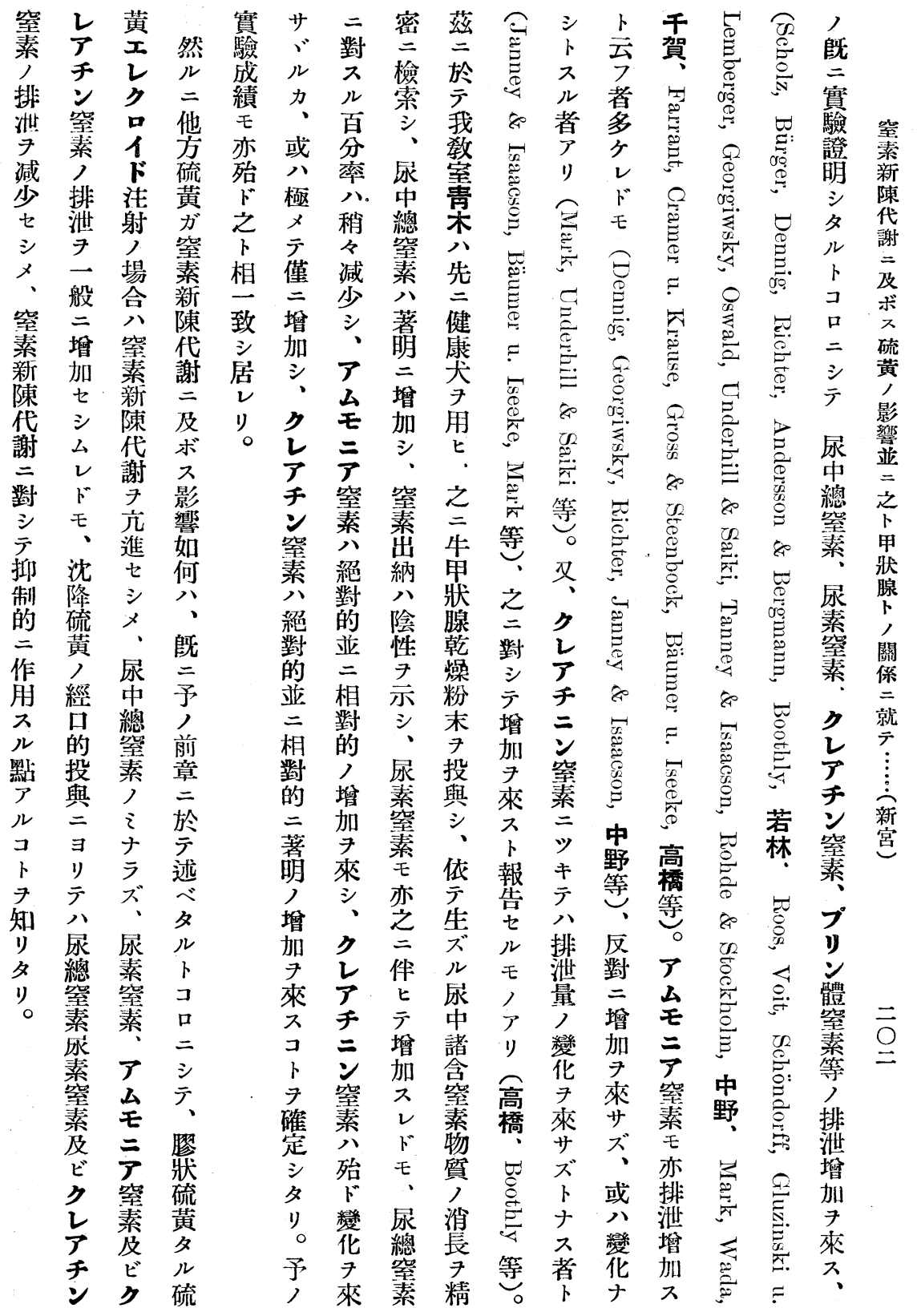




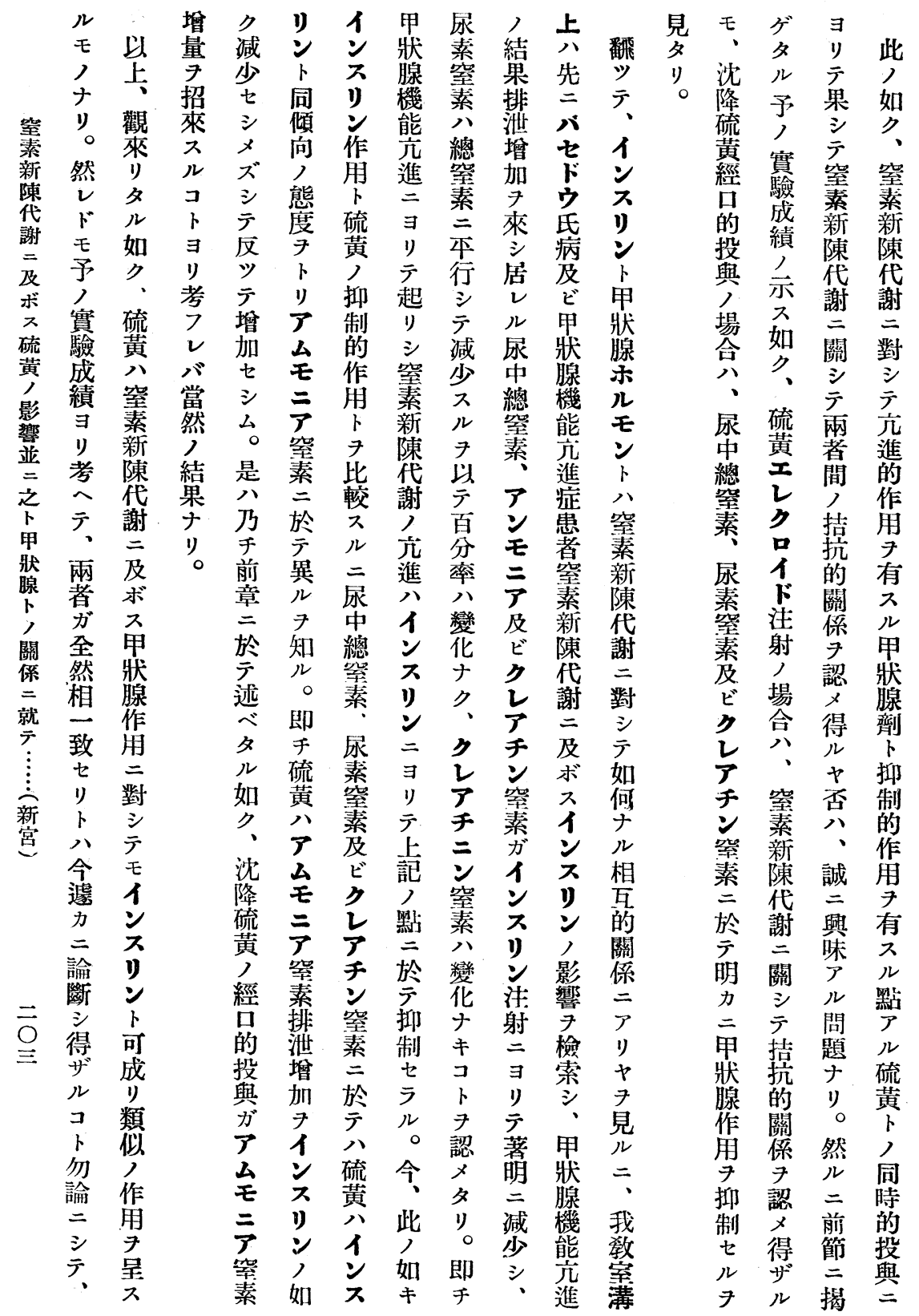




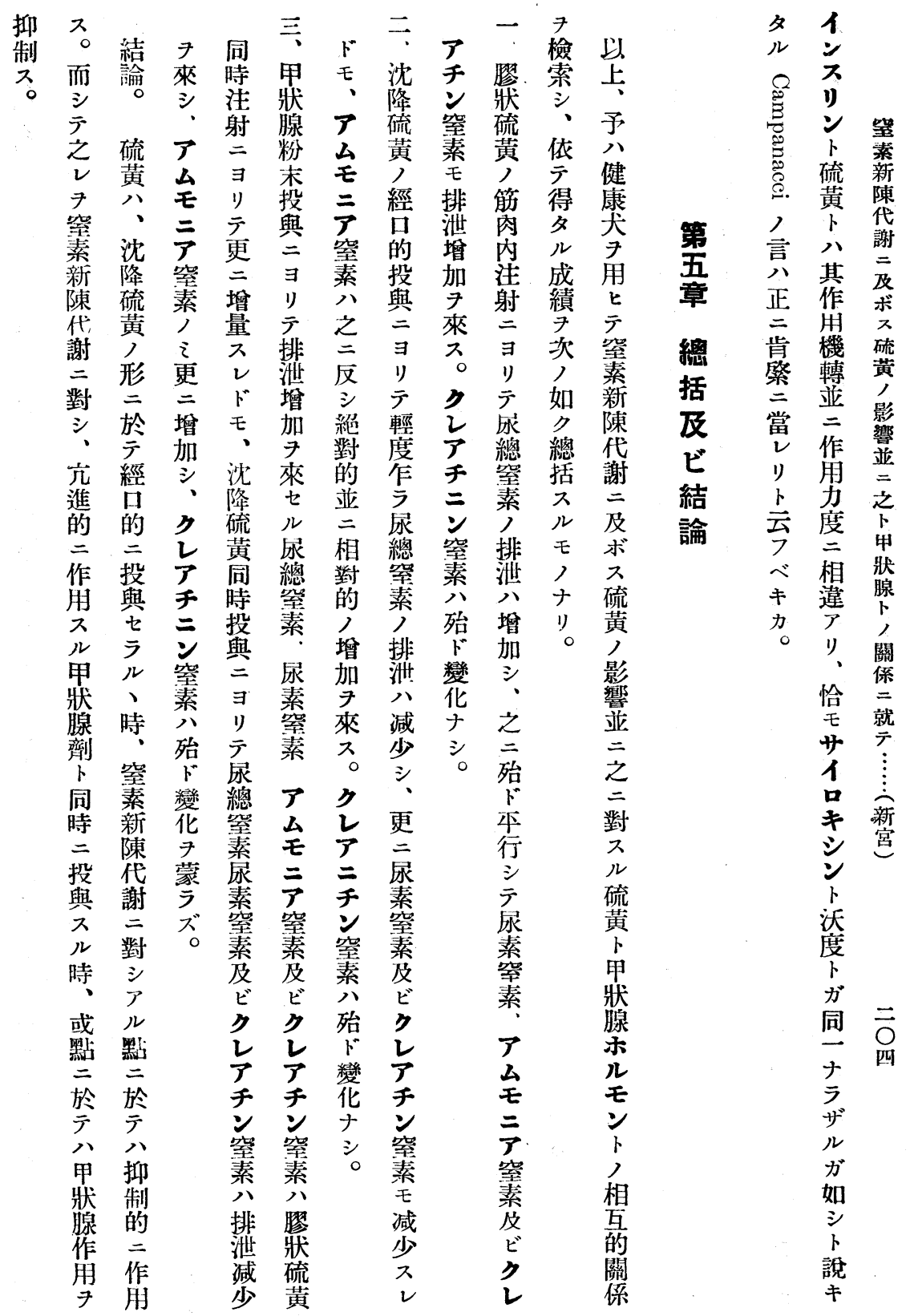




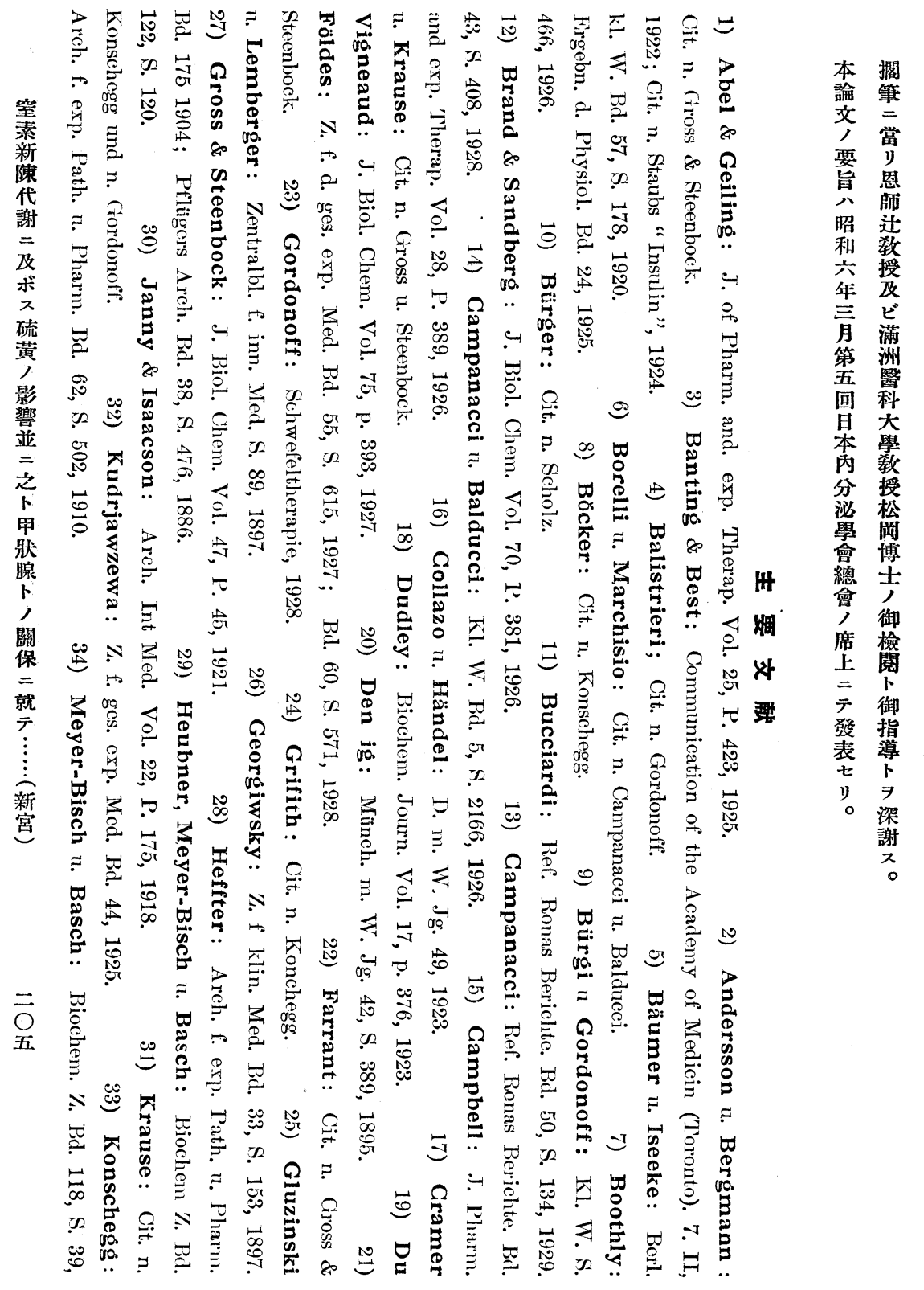




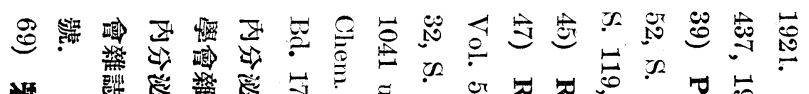

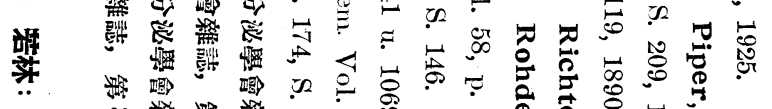

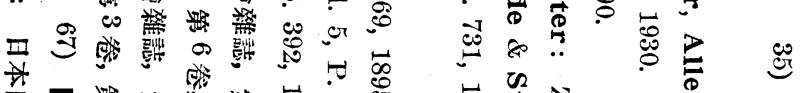

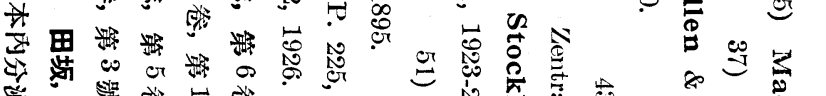

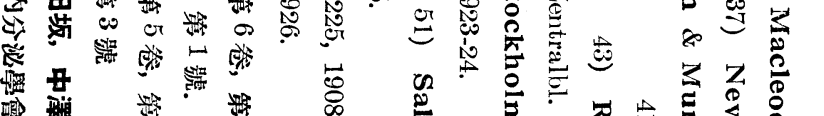

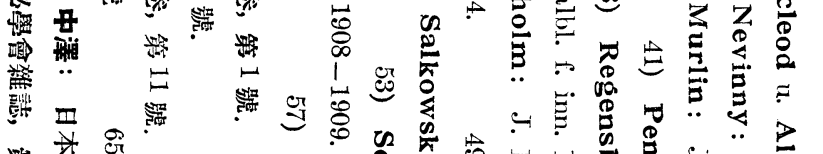

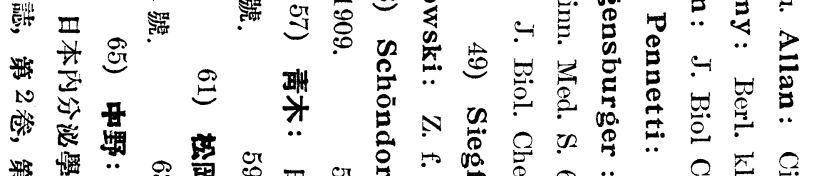

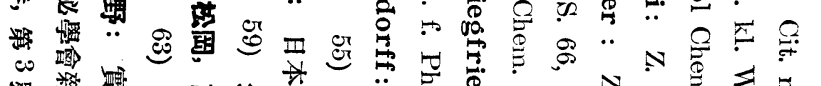

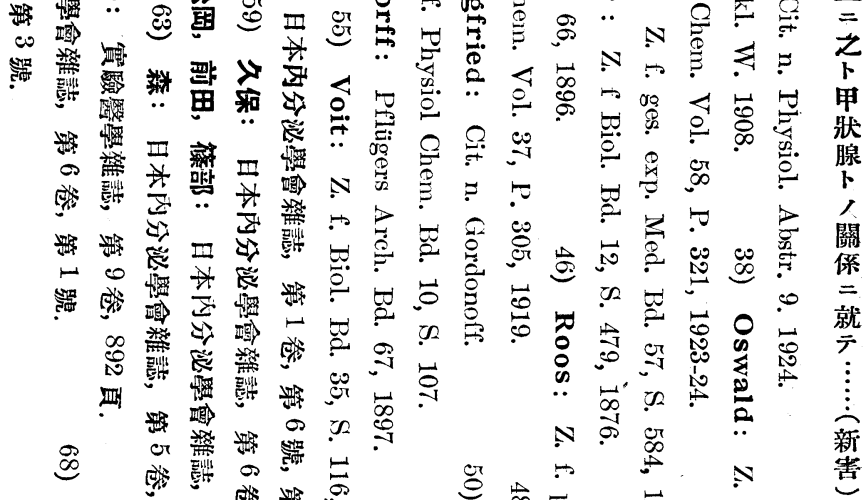

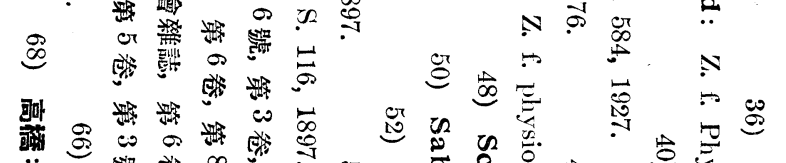

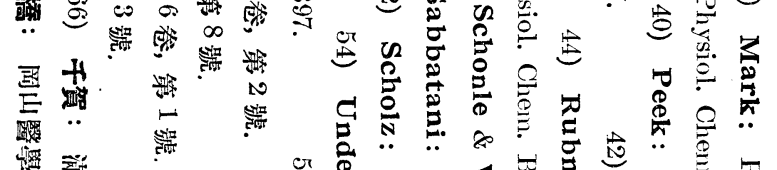

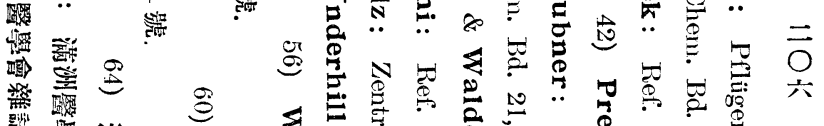

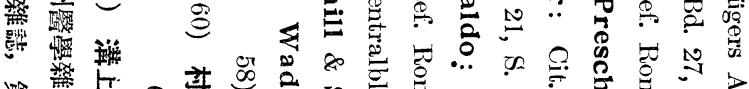

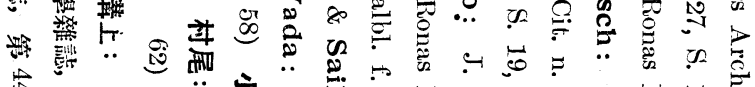

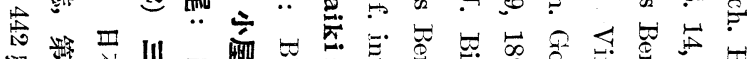

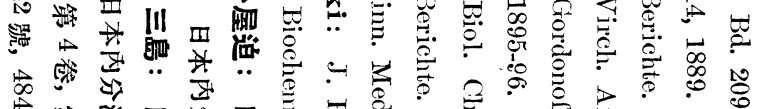

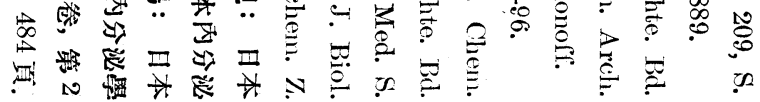


Rindenteile beider Nebemieren zu, erreichte meistens nach 3-5 Tagen sein Maximum und blieb lange in diesem Zustand, wie das schon bei der Exstirpation beider Nebennieren zu sehen war. Der Ca-gehalt im Serum nahm nach dem Kauterisieren zeitweilig ab. Doch ging seine Schwankung beinaheparallel mit der Konzentration des Serumeiweisses.

Der K/Ca-Quotient zeigte deutliche Zunahme, und diese Zunahme war nach dem Verlauf von 2 Wochen noch vorhanden.

4) Die Bestimmung des Glykogengehaltes in Leber und Muskel wurde an Kaninchen, deren $\mathrm{K}$-gehalt im Serum infolge Exstirpation beider Nebennieren deutliche Zunahme aufgewiesen hatte, am 16-17. Tag nach der Exstirpation vorgenommen. Es war dabei den Kontrolltieren gegenüber deutliche Abnahme des Glykogengehaltes zu konstatieren.

(Autoreferat)

\title{
Ueber den Einfluss des Schwefels auf den Stick- stoffwechsel und die Beziehung zwischen Schwefel und Schilddrüse darauf.
}

\author{
Von \\ Dr. S. Shingu. \\ (Aus der I. med. Klinik der Kaiserl. Universität zu Kyoto in Japan. \\ Direktor : Prof. Dr. K. Tsuji.)
}

Die Beziehungen zwischen Schwefel und Inkrete werden neuerdings von verschiedenen Seiten untersucht. Auch aus der hiesigen Klinik sind bereits verschiedene Experimente darüber veröffentlicht worden. Um zur Klärung der Schwefelwirkung auf den N-stoffwechsel sein Scherflein beizutragen, hat der Verfasser an gesunden erwachsenen Hündinnen den vorliegenden Versuch vorgenommen.

Die Resultate sind die folgenden:

1) Wenn man kolloidalen Schwefel intramusculär injiziert, so steigert sich die Gesamt-N-ausscheidung im Harn deutlich. Fast 
parallel damit vermehren sich das Urea-, Ammoniak- und Kreatin-N. Das Kreatinin-N zeigt dabei keine Veränderung.

2) Durch Fütterung mit präcipitiertem Schwefel nimmt, wenn auch nur leichtgradig, das Gesamt-N ab. Auch das Urea- und Kreatin- $\mathrm{N}$ vermindern sich, während sich das Ammoniak- $\mathrm{N}$ in absoluter Menge sowie prozentuell im Rahmen des Gesamt-N vermehrt. Das Kreatinin-N verändert sich dabei nicht.

3) Die durch Schilddrüsenpulververabreichung gesteigerte Gesamt-, Urea-, Ammoniak- und Kreatin-N-ausscheidung im Harn werden durch Injektion kolloidalen Schwefels noch verstärkt, aber durch Fütterung mit präcipitiertem Schwefel scheint die Steigerung der Gesamt-, Urea- und Kreatin-N-ausscheidung gehemmt zu werden. Es vermehrt sich dabei nur das Ammoniak-N, während das Kreatinin- $\mathrm{N}$ unverändert bleibt.

Aus den obigen Ergebnissen darf man den Schluss ziehen, dass der Schwefel, wenn er in Form von präcipitiertem Schwefel per os verabreicht wird, den $\mathrm{N}$-stoffwechsel in gewissen Punkten hemmend beeinflusst und wenn gleichzeitig mit Schilddrüsenpulver eingegeben, in gewissen Punkten die Schilddrüsenwirkung auf den $\mathrm{N}$-stoffwechsel hemmt.

(Autoreferat) 